\title{
WHAT LIES BENEATH?
}

\section{A TIME-VARYING FAVAR MODEL FOR THE UK TRANSMISSION MECHANISM}

by Haroon Mumtaz, Pawel Zabczyk and Colin Ellis 


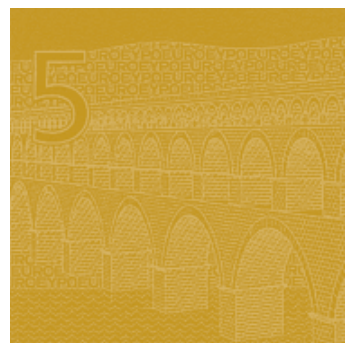

\title{
WORKING PAPER SERIES
}

NO I320 / APRIL 20II

\section{WHAT LIES BENEATH?}

\section{A TIME-VARYING FAVAR MODEL FOR THE UK TRANSMISSION MECHANISM ${ }^{\prime}$}

\author{
by Haroon Mumtaz ${ }^{2}$, Pawel Zabczyk ${ }^{3}$ \\ and Colin Ellis ${ }^{4}$
}

NOTE: This Working Paper should not be reported as representing the views of the European Central Bank (ECB).

The views expressed are those of the authors and do not necessarily reflect those of the ECB.

This paper can be downloaded without charge from http://www.ecb.europa.eu or from the Social Science Research Network electronic library at http://ssrn.com/abstract_id $=1789603$.

I The views expressed here are those of the authors and do not necessarily reflect those of the Bank of England or the Monetary Policy Committee. Note, that an earlier version of this paper appeared as a Bank of England Working Paper 364. For helpful comments and suggestions, we'd like to thank Jean Boivin, Alex Bowen, Bianca De Paoli, Stephen Millard, Miles Parker, Simon Price, Lucrezia Reichlin, Ricardo Reis, Garry Young two anonymous referees and seminar participants at the 2008 MMF conference and the 2009 RES conference. All remaining errors are ours. 2 Centre for Central Banking Studies, Bank of England. 3 Corresponding author: Bank of England and European Central Bank, Kaiserstrasse 29, D-603II Frankfurt am Main, Germany; phone number: +4969 1344 6819; e-mail: pawel.zabczyk@ecb.europa.eu 
(C) European Central Bank, 2011

\section{Address}

Kaiserstrasse 29

60311 Frankfurt am Main, Germany

Postal address

Postfach 160319

60066 Frankfurt am Main, Germany

\section{Telephone}

+496913440

Internet

http://www.ecb.europa.eu

Fax

+496913446000

All rights reserved.

Any reproduction, publication and reprint in the form of a different publication, whether printed or produced electronically, in whole or in part, is permitted only with the explicit written authorisation of the ECB or the authors.

Information on all of the papers published in the ECB Working Paper Series can be found on the ECB's website, http://www. ecb.europa.eu/pub/scientific/wps/date/ html/index.en.html

ISSN 1725-2806 (online) 


\section{CONTENTS}

Abstract

Non technical summary

1 Introduction

2 The empirical model

2.1 Identification of structural shocks

2.2 Estimation

2.3 Data

3 Results

3.1 Model comparison

3.2 The Estimated factors and stochastic volatility

3.3 Impulse response to a monetary policy shock

4 Forecast error variance decomposition

5 Conclusions

Appendices

References 


\begin{abstract}
This paper uses a time-varying Factor Augmented VAR to investigate the evolving transmission of monetary policy and demand shocks in the UK. Simultaneous estimation of time-varying impulse responses of a large set of macroeconomic variables and disaggregated prices suggest that the response of inflation, money supply and asset prices to monetary policy and demand shocks has changed over the sample period. In particular, during the post-1992 inflation targeting period, monetary policy shocks started having a bigger impact on prices, a smaller impact on activity and began contributing more to overall volatility. In contrast, demand shocks had the largest impact on these variables before the 1990s. We also document changes in the response of disaggregated prices, with the median reaction to contractionary policy shocks becoming more negative and the distribution more dispersed post-1992.
\end{abstract}

Keywords: Transmission mechanism, monetary policy, Factor Augmented VAR, timevarying coefficients, sign restrictions.

JEL classification: C38, E44, E52 


\section{Non-technical Summary}

How does an economy respond when shocks hit it, or when policymakers change interest rates? And can those responses change over time, if the underlying structure of the economy changes? These questions are of critical importance to macroeconomists and monetary policy makers around the world, as they go to the heart of how interest rates can be used to underpin growth and enshrine price stability. Unfortunately, standard empirical models that are used to examine how economies behave, and how they respond to shocks, are often too small to accommodate the rich underlying tapestry of the economy, or too inflexible to allow for the fact that the economy may today respond very differently to an unexpected change in interest rates, compared with twenty or thirty years ago.

In the past, economists have sometimes struggled to meet these challenges sufficiently well, for instance because they use small scale models - typically including three or four data series such as GDP, an inflation measure, and policy rates - that are easy to estimate but run the risk of misrepresenting the economy. In particular, these types of models often ignore asset prices or monetary aggregates, or only include them in a very limited fashion. This includes work that has tried to allow for the changing structure of the economy, as much of this literature only examines whether the dynamics of output or inflation have changed.

This paper seeks to address these challenges using a relatively new type of statistical model, which encompasses lots of different information and data, but remains relatively straightforward to use. In addition, our modelling approach allows for changes in the underlying structure of the economy, rather than imposing one configuration over the whole of our sample. This flexible approach is important, as we address these challenges from a UK perspective, examining the behavior and response of the economy from 1975 to 2005. During this period the UK economy changed in many significant ways, not least in the shift to inflation targeting in 1992 following sterling's exit from the European exchange rate mechanism (ERM), and the Bank of England's subsequent independence in 1997. In light of this, the flexibility of our approach is a key strength, as is our ability to capture the rich variety of UK macroeconomic data that are available, which reduces the chance that our model is misspecified.

Using quarterly UK data, we apply our modelling approach and uncover several important findings about the nature and structure of the UK economy. Using sign restrictions to identify two types of shocks - that is, constraining the initial response of variables to aggregate demand and monetary policy surprises - our results indicate that the structure of the UK economy has changed significantly, and suggest that models which do not allow for timevariation will be misleading. In addition, there is significant evidence that the shift to inflation targeting in 1992 had a material impact on the effectiveness of monetary policy: prior to that time, monetary policy appears to have had almost no impact on inflation, but after the change in regime inflation falls following an unexpected increase in interest rates. Furthermore, we observe that relative prices - the prices of individual goods and services, 
relative to the aggregate - are also more dispersed than prior to 1992. At the same time, unexpected movements in demand now appear to have far less impact on UK inflation than they did before 1992, suggesting that the move to inflation targeting affected the way that households and businesses have responded to shocks. And, in aggregate, monetary policy appears to have been much more important since 1992 in driving movements in output, inflation, monetary aggregates and asset prices than it was before the introduction of inflation targeting.

Overall, our results suggest that the move to inflation targeting has had a clear and lasting impact on the structure of the UK economy, and possibly the behavior of firms and households. Unexpected movements in demand now have much less impact on the economy as a whole, consistent with the credibility of monetary policy. In addition, our model offers a new approach for policymakers who want to take time-variation seriously, while also allowing them to examine the impact of policy on a wide range of factors including equity prices, unemployment and money growth. 


\section{Introduction}

Over the last three decades, the United Kingdom has undergone major structural changes. These changes could have occurred at the same time as shifts in the properties of structural shocks and, arguably, both would have affected the transmission mechanism of policy. ${ }^{1}$ Quantifying the impact of such changes and identifying the key factors driving them are of first-order importance for economists and policy-makers alike. To this end, this paper proposes an empirical model which allows for the simultaneous estimation of time-varying impulse responses of a large set of variables to structural shocks.

The possibility of a changing transmission mechanism has been investigated for the UK largely via small scale vector autoregressions (VARs) that typically include three or four endogenous variables. For example, Benati (2008) uses a time-varying VAR in UK output, inflation, short-term interest rate and broad money and shows that there is little significant change (across time) in the response of these variables to a monetary policy shock. Similarly, Castelnuovo and Surico (2006) use a small scale VAR estimated on the pre and post-inflation targeting period to gauge the changing response of inflation to monetary policy shocks.

Note that while these papers provide results for the changing dynamics of variables such as output and inflation, there is little existing evidence on the changing transmission of shocks to asset prices, measures of real activity other than GDP, measures of inflation other than CPI and RPI, different monetary aggregates and sectoral prices and quantities. In addition, Benati and Surico (2009) suggest that small-scale VARs may suffer from model misspecification - with omitted variables potentially distorting estimates of reduced form VAR coefficients or hindering the correct identification of structural shocks.

The purpose of this paper is to re-examine the evolution of the UK monetary transmission mechanism using an empirical framework that incorporates substantially more information than the standard three or four variable-variable model used in most previous studies. In particular, we employ an extended version of the factor-augmented VAR (FAVAR) introduced in Bernanke et al. (2005). This model includes information from a large number of macroeconomic indicators representing various dimensions of the economy. Our extensions include allowing for time variation in the coefficients and stochastic volatility in the variances of the shocks. Our formulation has two clear advantages over previous studies: (i) we identify structural shocks using a model that incorporates around 350 macroeconomic and financial variables, hence making it less likely that our setup suffers from the shortcomings discussed above, (ii) our model allows us to estimate time-varying impulse responses for each of the variables contained in our panel. Therefore, we are able to derive results for the variation in responses of a wide variety of variables to the identified shocks. In particular, this paper

\footnotetext{
${ }^{1}$ A number of papers including Benati (2004), Mumtaz and Surico (2008) and Benati (2008) have shown that the 1970s and the 1980s were characterized by volatile inflation and output growth. In addition, the persistence of inflation was estimated to be high during this period. In contrast the period after the introduction of inflation targeting in 1992 was associated with low inflation and output volatility and low inflation persistence.
} 
not only provides evidence on the possible change in responses of the main macroeconomic variables, but also on the time-varying responses of components of the consumption deflator. The proposed time-varying FAVAR model is estimated on quarterly UK data spanning the period 1975-2005. We use sign restrictions to identify a monetary policy shock and an aggregate demand shock. Our main results are as follows:

- Based on model selection criteria, a fixed coefficient FAVAR model is rejected in favor of the proposed model with time-varying parameters.

- The response of inflation measures to a monetary policy shock is estimated to have changed substantially over the sample period. The pre-1992 response to a contractionary policy shock is estimated to be close to zero while the response over the inflation targeting period is negative and statistically significant. The response of money supply and the long-term government bond yield to this shock displays a similar pattern, with the post-1992 response larger in magnitude.

- There is a substantial change in the response of inflation to an aggregate demand shock. While the response in the pre-1992 period to a positive demand shock was large and persistent, the inflation targeting regime is associated with a response which is smaller in magnitude.

- There is evidence that moments of cross-sectional distribution of the response of disaggregated prices to a monetary policy shock have shifted over time. The median of the price distribution is more negative now than in the late 1970s. Similarly, the distribution is more dispersed than in the past.

- Counterfactual experiments suggest that changes in the impulse response functions are linked to changes in the parameters of the FAVAR interest rate equation pointing to the role played by monetary policy.

- A forecast error variance decomposition exercise indicates that the monetary policy shock became important for measures of real activity, inflation, money and asset prices after 1992, while the demand shock made an important contribution in the pre-1992 period.

The paper is organized as follows: the next section presents the empirical model, section 3 discusses the estimated time-varying impulse responses to a monetary policy and demand shock, a time-varying forecast error variance decomposition is shown in section 4 and section 5 concludes. 


\section{The Empirical Model}

Consider any model based on the standard, three-equation New Keynesian core. Bernanke et al. (2005) argue that assumptions made about the information structure are crucial when deciding whether the dynamics of such a model can be described by a vector autoregression. In particular, if it is assumed that the specific data series included in the VAR correspond exactly to the model variables and are observed by the central bank and the econometrician, then the VAR model provides an adequate description of the theoretical model. However, both these assumptions are difficult to justify. First, measurement error implies that measures of inflation and output are less than perfect proxies for model variables. Of course, this problem is much more acute for unobserved variables such as potential output. Furthermore, for broad concepts like economic activity and inflation there exists a multitude of observable indicators none of which will be able to match the theoretical construct precisely. Second, it is highly likely that the researcher only observes a subset of the variables examined by the monetary authority.

Note that measurement error and omitted variables can potentially affect small-scale VAR analyses of changes in the transmission of structural shocks quite acutely. When examining time variation in impulse responses, the assumptions about the measurement of model variables and the information set used by model agents apply at each point in time and are more likely to be violated. If important information is excluded from the VAR, this can affect inference on the temporal evolution of impulse responses and lead to misleading conclusions about changes in the transmission mechanism.

The obvious solution to this problem is to try and include more variables in the VAR. However, the degrees of freedom constraint becomes binding quite quickly in standard datasets. ${ }^{2}$ Bernanke et al. (2005) suggest a more practical solution. They propose a 'Factor-Augmented' VAR (FAVAR) model, where factors from a large cross section of economic indicators are included as extra endogenous variables in a VAR. ${ }^{3}$ These factors proxy the information set of the central bank (part of) which may have been inadvertently excluded from the small scale VAR model. We extend the FAVAR model along two dimensions.

- First, we allow the dynamics of the system to be time-varying to capture changes in the propagation of structural shocks as a result of shifts in private sector behavior and/or monetary policy preferences.

- Second, our specification incorporates heteroscedastic shocks which account for variations in the volatility of the underlying series.

This extended FAVAR model provides a flexible framework to examine changes in the transmission of structural shocks. Moreover, our time-varying FAVAR model is less susceptible to

\footnotetext{
${ }^{2}$ This problem is even more acute in time-varying VARs as they usually impose a stability constraint (at each point in time) and this is less likely to be satisfied as the number of variables in the VAR increases.

${ }^{3}$ See also Forni and Gambetti (2010) for a recent application to US data based on sign-restrictions.
} 
problems created by omitted variables and therefore provides a robust framework to examine changes in the transmission mechanism. As we discuss below, the results obtained from our model differ substantially from those obtained using a standard small-scale time-varying VAR.

More formally, our FAVAR model for the UK economy can be written in state space form. Consider first the observation equation

$$
\left(\begin{array}{c}
X_{1, t} \\
\cdot \\
\cdot \\
X_{N, t} \\
R_{t}
\end{array}\right)=\left(\begin{array}{cccc}
\Lambda^{11} & \cdot & \Lambda^{K 1} & \Psi^{11} \\
\cdot & \cdot & \cdot & \cdot \\
\cdot & \cdot & \cdot & \cdot \\
\Lambda^{1 N} & \cdot & \Lambda^{K N} & \Psi^{1 N} \\
0 & \cdot & 0 & 1
\end{array}\right)\left(\begin{array}{c}
F_{t}^{1} \\
F_{t}^{2} \\
\cdot \\
F_{t}^{K} \\
R_{t}
\end{array}\right)+\left(\begin{array}{c}
e_{1 t} \\
e_{2 t} \\
\cdot \\
e_{N t} \\
0
\end{array}\right)
$$

where $X_{t}$ is a panel of variables that contain information about real activity, inflation, money and asset prices in the UK (see data subsection below) while $F_{t}^{1}$ to $F_{t}^{K}$ denote the $K$ latent factors. We assume that these factors capture the dynamics of the UK economy and the $\Lambda$ 's denote the factor loadings. Along similar lines as in Bernanke et al. (2005) the bank rate $R_{t}$ is the 'observed factor'. We stress that the structure of the loading matrix implies that some of the variables are allowed to have a contemporaneous relationship with the short term interest rate - i.e. $\Psi \neq 0$ for data series that are expected to react promptly to monetary policy actions.

As we describe below, time variation is introduced into the model by allowing for drift in the coefficients and the error covariance matrix of the transition equation. Note that an alternative way of modelling time variation is to allow the factor loadings $(\Lambda$ and $\Psi)$ to drift over time. ${ }^{4}$ There are, however, several reasons why we do not adopt this alternative specification. First, such a setup implies that any time variation in the dynamics of each factor and the volatility of shocks to each factor is driven entirely by the drift in the associated factor loading. This assumption is quite restrictive, especially as it only allows changes in the mean and persistence of each factor to occur simultaneously with changes in the volatility of the shocks. Second, this model implies a much larger computational burden as the Kalman filter and a backward recursion have to be employed for each underlying series. Finally, apart from the computational costs, this specification implies that the dynamics of observed factors are time invariant and, in particular, that the central bank always reacts in the same way to the "state of the economy" (captured by the latent factors). Such an assumption is hard to justify given our sample period (1975Q1 to 2005Q1) and would be rather restrictive in a model designed to investigate the changing impact of monetary policy.

Equally, allowing for time variation in both, the factor loadings and the coefficients of the transition equation would entail serious identification problems since there would be three time-varying unobserved components, i.e. $\Gamma_{t}=\left[\Lambda_{t}, \Psi_{t}\right], \phi_{t}$ and $F_{t}$. However, substituting

\footnotetext{
${ }^{4}$ See Del Negro and Otrok (2008) for this kind of approach in a different context.
} 
the transition equation (2) into the observation equation (1) imparts a restricted form of time variation also in the factor loadings. This interaction between the loadings and the time-varying coefficients of the factors has the potential to generate rich dynamics for the impulse response functions of the underlying series.

As described below, time-variation is introduced into the model by allowing for drift in the coefficients and the error covariance matrix of the transition equation. More specifically, the transition equation of the system is a time-varying VAR model of the following form

$$
Z_{t}=\sum_{l=1}^{L} \phi_{l, t} Z_{t-l}+v_{t}
$$

where $Z_{t}=\left\{F_{t}^{1}, F_{t}^{2}, . . F_{t}^{K}, R_{t}\right\}$ and $L$ is fixed at 2 . We further postulate the following law of motion for the coefficients $\phi$

$$
\phi_{t}=\phi_{t-1}+\eta_{t}
$$

and the innovation $\left(v_{t}\right)$ covariance matrix is factored as

$$
\operatorname{VAR}\left(v_{t}\right) \equiv \Omega_{t}=A_{t}^{-1} H_{t}\left(A_{t}^{-1}\right)^{\prime}
$$

where the time-varying matrices $H_{t}$ and $A_{t}$ evolve as random walks.

The model described by equations 1 and 2 can incorporate a large amount of information about the UK economy. In particular, if the factors in equation 1 contain relevant information not captured by the three variables used in 'standard' VAR studies (eg Primiceri (2005)) then one might expect structural shocks identified within the current framework to be more robust. Our flexible specification for the transition equation also implies that the model accounts for the possibility of structural breaks in the dynamics that characterize the economy.

\subsection{Identification of Structural Shocks}

We identify two shocks: a monetary policy shock, and an aggregate demand shock. Following Canova and Nicolo (2002) and Uhlig (2005), the shocks are identified by placing contemporaneous sign restrictions on the response of some of the variables in $X_{t}$ to an innovation to $R_{t}$. Our procedure works as follows: let $\Omega_{t}=P_{t} P_{t}^{\prime}$ be the Cholesky decomposition of the VAR covariance matrix $\Omega_{t}$, and let $\tilde{A}_{0, t} \equiv P_{t}$. We draw an $N \times N$ matrix, $J$, from the $N(0,1)$ distribution. We take the $Q R$ decomposition of $J$, which gives us a candidate structural impact matrix as $A_{0, t}=\tilde{A}_{0, t} Q$. Next we compute the contemporaneous impulse response of 

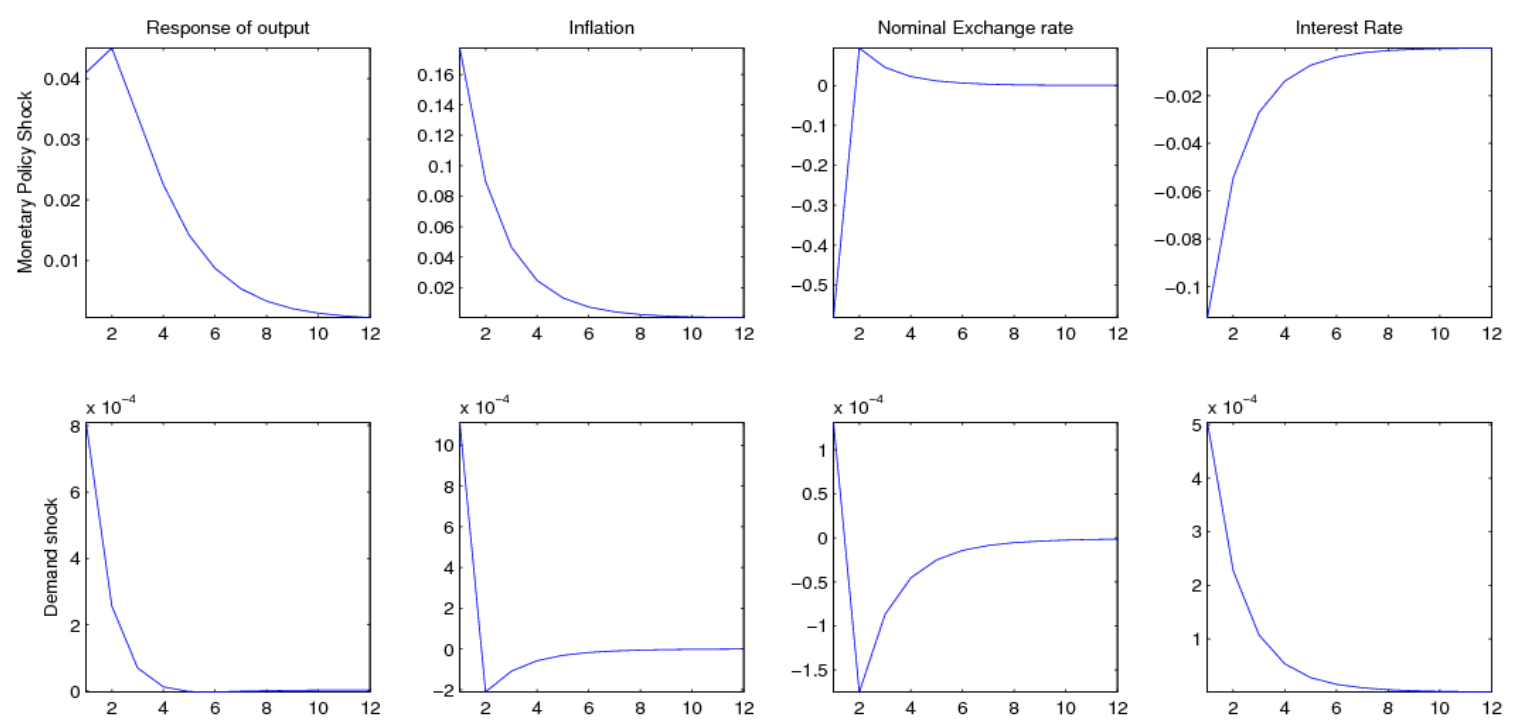

Figure 1: Impulse response to a monetary policy shock (top panel) and demand shock (bottom panel) using the model in Lubik and Schorfheide (2006).

$X_{1, t}, \ldots X_{N, t}$ as

$$
\left(\begin{array}{c}
\Delta X_{1, t} \\
\cdot \\
\cdot \\
\Delta X_{N, t} \\
\Delta R_{t}
\end{array}\right)=\left(\begin{array}{cccc}
\Lambda^{11} & \cdot & \Lambda^{K 1} & \Psi^{11} \\
\cdot & \cdot & \cdot & \cdot \\
\cdot & \cdot & \cdot & \cdot \\
\Lambda^{1 N} & \cdot & \Lambda^{K N} & \Psi^{1 N} \\
0 & \cdot & 0 & 1
\end{array}\right) \times A_{0, t}
$$

where $\Delta X_{i, t}$ denotes the response of the $i$-th variable. We check if these satisfy our sign restrictions. If this is the case we store $A_{0, t}$ and repeat the procedure until we have 100 $A_{0, t}$ matrices that satisfy the sign restrictions. Out of these 100 stored $A_{0, t}$ matrices we retain the matrix with elements closest to the median across these 100 estimates. If the contemporaneous sign restrictions are not satisfied, we draw another $J$ and repeat the above.

We motivate our sign restrictions using a structural, two-country model described in Lubik and Schorfheide (2006) - an estimated, open-economy extension of the standard, threeequation New Keynesian workhorse. The model-implied impulse responses to monetary policy and demand shocks are given in figures 1 . In light of these impulse responses we impose the following: (1) contractionary monetary policy shocks are assumed to increase R, reduce GDP growth, reduce inflation and lead to a nominal effective exchange rate appreciation on impact; (2) positive demand shocks have a positive contemporaneous impact on GDP growth, inflation and the nominal rate. With this minimal set of restrictions, we are able to disentangle the two structural shocks.

Our identification method has a number of advantages over Bernanke et al.'s (2005) recursive scheme. First, contemporaneous sign restrictions allow us to be relatively 'agnostic' about the impact of structural shocks (beyond the contemporaneous effects) while simultaneously 
imposing more structure than a Cholesky decomposition. Second, by using our identification scheme we are able to easily identify structural shocks other than those to monetary policy.

\subsection{Estimation}

We estimate the model using Bayesian methods. A detailed description of the prior and posterior distributions is provided in the appendix. Here we summarize the estimation algorithm. The Gibbs sampler cycles through the following steps:

1. Given initial values for the factors, simulate the VAR parameters and hyperparameters

- The VAR coefficients $\phi_{t}$ and the off-diagonal elements of the covariance matrix $\alpha_{t}$ are simulated by using the methods described in Carter and Kohn (1994)

- The volatilities of the reduced form shocks $H_{t}$ are drawn using the date by date blocking scheme introduced in Jacquier et al. (2002).

- The hyperparameters are drawn from their respective distributions.

2. Given initial values for the factors draw the factor loadings $(\Lambda$ and $\Psi)$ and the variance of the idiosyncratic components.

- Given data on $R_{t}$ and $X_{i, t}$ standard results for regression models can be used and the coefficients and the variances are simulated from a normal and inverse gamma distribution.

3. Simulate the factors conditional on all the other parameters

- This is done in a straightforward way by employing the methods described in Bernanke et al. (2005) and Kim and Nelson (1999).

4. Go to step 1.

We use 55,000 iterations in this MCMC algorithm discarding the first 45,000 as burn-in. The cumulated means of the retained draws (see appendix) show little variation which provides some evidence of algorithm convergence.

\subsubsection{Computation of Impulse Response Functions}

We calculate the impulse responses $\Delta_{t}$ of $F_{t}^{1}, F_{t}^{2}, \ldots F_{t}^{K}$ and $R_{t}$ to the monetary policy shock and the demand shock for each quarter. With these in hand, the time-varying impulse 
responses of each underlying variable can be easily obtained using the observation equation (1) of the model. That is, the impulse responses of $X_{1, t}, \ldots X_{N, t}$ are computed as:

$$
\left(\begin{array}{cccc}
\Lambda^{11} & \cdot & \Lambda^{K 1} & \Psi^{11} \\
\cdot & \cdot & \cdot & \cdot \\
\cdot & \cdot & \cdot & \cdot \\
\Lambda^{1 N} & \cdot & \Lambda^{K N} & \Psi^{1 N} \\
0 & \cdot & 0 & 1
\end{array}\right) \times\left(\begin{array}{c}
\Delta_{t}^{F_{t}^{1}} \\
\cdot \\
\Delta_{t}^{F_{t}^{K}} \\
\Delta_{t}^{R_{t}}
\end{array}\right)
$$

Given the presence of time-varying parameters in the transition equation, computation of impulse response functions has to take into account the possibility of parameter drift over the impulse response horizon. Therefore, following Koop et al. (1996), we define the impulse response functions at each date as $\Delta_{t}$

$$
\Delta_{t+k}=E\left(Z_{t+k} \mid \Xi_{t+k}, \mu_{M P}\right)-E\left(Z_{t+k} \mid \Xi_{t+k}\right)
$$

where $\Xi$ denotes all the parameters and hyperparameters of the VAR and $k$ is the horizon under consideration. Equation (5) states that the impulse response functions are calculated as the difference between two conditional expectations. The first term in equation (5) denotes a forecast of the endogenous variables conditioned on a monetary policy shock $\mu_{M P}$. The second term is the baseline forecast, i.e. conditioned on the scenario where the monetary policy shock equals zero. Therefore, in effect, equation (5) integrates out future uncertainty in the VAR parameters. The conditional expectations in (5) are computed via Monte Carlo integration for 1000 replications of the Gibbs sampler. Details on the Monte Carlo integration procedure can be found in Koop et al. (1996).

\section{$2.3 \quad$ Data}

Our dataset is quarterly running from 1964 Q1 to 2005 Q1. As described in the appendix, we use the first 40 observations as a training sample with the estimation carried out starting 1975Q1. The dataset comprises around 60 macroeconomic UK data series. It includes activity measures such as GDP, consumption and industrial production, various price measures including RPI, CPI and the GDP deflator, as well as money and asset price data. In addition to these macro variables, we included a large number of disaggregated deflator and volume series for consumers' expenditure. The Office for National Statistics (ONS) publishes around 140 subcategories of consumer expenditure data both in volume and deflator terms, going back to the 1960s. This gives us a ready-made collection of consistent disaggregated price (and volume) data over a long time period. Further details on the dataset are provided in the appendix to the paper. 


\begin{tabular}{lrrr}
\hline & $D I C$ & $\bar{D}$ & $p_{D}$ \\
\hline \hline Time-varying parameter FAVAR with 1 factor & 20199 & 19481 & 718 \\
Fixed coefficients FAVAR with 1 factor & 42107 & 41757 & 350 \\
\hline \hline Time-varying parameter FAVAR with 2 factors & 15715 & 14654 & 1061 \\
Fixed coefficients FAVAR with 2 factors & 35905 & 35225 & 680 \\
\hline \hline Time-varying parameter FAVAR with 3 factors & 22956 & 18330 & 4626 \\
Fixed coefficients FAVAR with 3 factors & 33214 & 32271 & 943 \\
\hline \hline
\end{tabular}

Table 1: Model Comparison via DIC. Best fit indicated by lowest DIC.

\section{Results}

\subsection{Model Comparison}

In order to select the number of latent factors and to assess the importance of time-variation that we introduce in the parameters of the FAVAR model, we compare our benchmark model (see equation 1) with a version of the model that assumes fixed parameters via the deviance information criterion $(D I C)$. The $D I C$ is a generalization of the Akaike information criterion - it penalizes model complexity while rewarding fit to the data. The DIC is defined as

$$
D I C=\bar{D}+p_{D}
$$

The first term $\bar{D}=E\left(-2 \ln L\left(\Xi_{i}\right)\right)=\frac{1}{M} \sum_{i}\left(-2 \ln L\left(\Xi_{i}\right)\right)$ where $L\left(\Xi_{i}\right)$ is the likelihood evaluated at the draws of all of the parameters $\Xi_{i}$ in the MCMC chain. This term measures goodness of fit. The second term $p_{D}$ is defined as a measure of the number of effective parameters in the model (or model complexity). This is defined as $p_{D}=E\left(-2 \ln L\left(\Xi_{i}\right)\right)-$ $\left(-2 \ln L\left(E\left(\Xi_{i}\right)\right)\right)$ and can be approximated as $p_{D}=\frac{1}{M} \sum_{i}\left(-2 \ln L\left(\Xi_{i}\right)\right)-\left(-2 \ln L\left(\frac{1}{M} \sum_{i} \Xi_{i}\right)\right) .5$ Note that the model with the lowest estimated $D I C$ is preferred.

Estimation of the DIC requires evaluating the likelihood function for each MCMC iteration. ${ }^{6}$ Calculation of the likelihood function for the time-varying FAVAR with stochastic volatility is complicated due to the non-linear interaction of the volatility with levels in equation 2 . We use a particle filter to evaluate the likelihood for each Gibbs draw. The Appendix presents a brief description of the particle filtering procedure.

Table 1 presents the estimated DIC for the time-varying parameter and fixed coefficient FAVAR. $^{7}$ In general model complexity $\left(p_{D}\right)$ is lower for the fixed coefficient FAVAR models.

\footnotetext{
${ }^{5}$ The first term in this expression is an average of -2 times the likelihood function evaluated at each MCMC iteration. The second term is ( -2 times) the likelihood function evaluated at the posterior mean.

${ }^{6}$ The main advantage of $D I C$ over Bayes factors is the difficulty in the accurate computation of the marginal likelihood in complex models. Although Monte Carlo-based methods such as the harmonic mean estimator can be used, the estimates tend to be influenced by outlying values of MCMC draws and can be inaccurate. The method described in Chib (1995) requires an additional Gibbs simulation for each parameter making its implementation difficult for the time-varying parameter model.

${ }^{7}$ Note that we limit the maximum number of factors to 3 for computational reasons. As common in the
} 

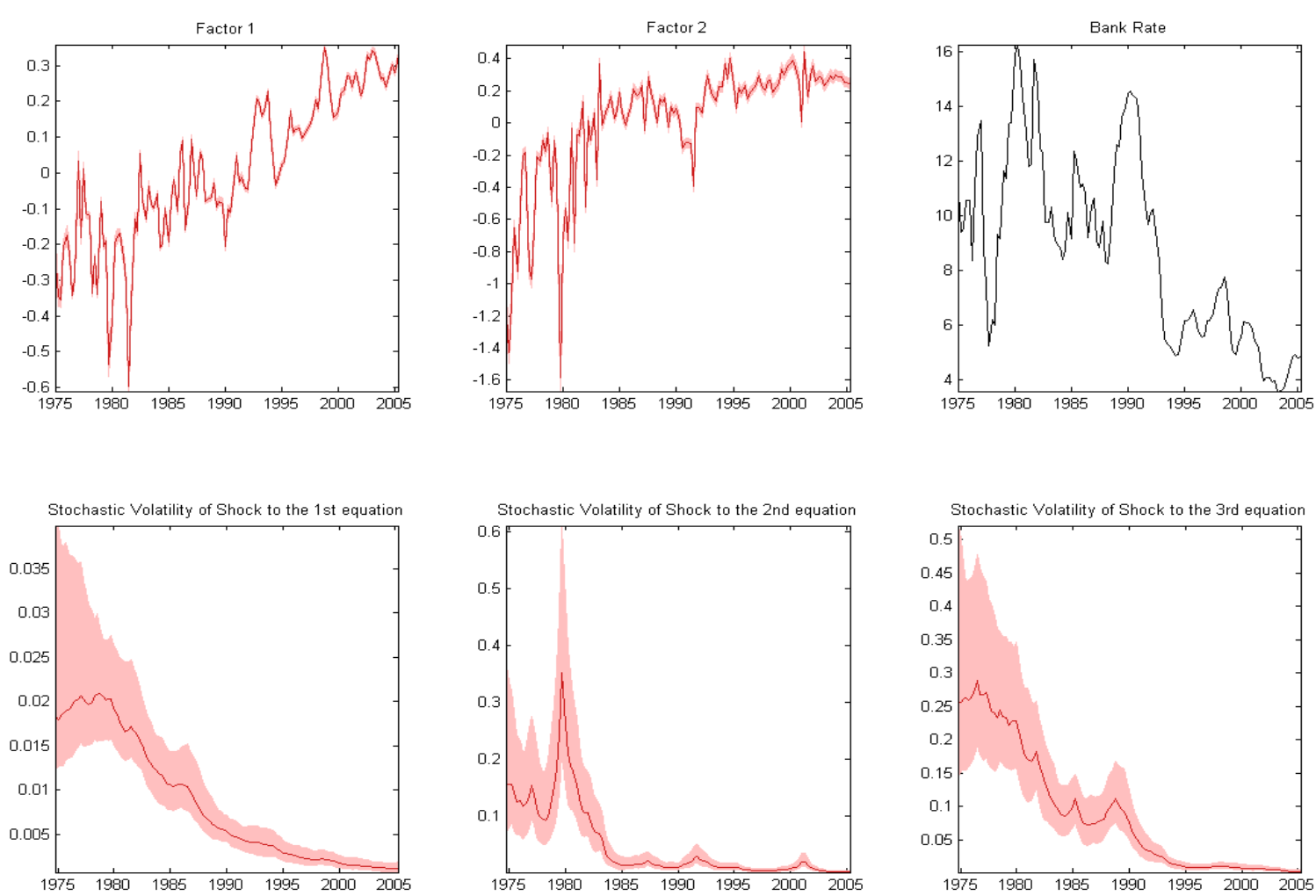

Figure 2: The estimated factors, the bank rate and the stochastic volatility of shocks to each transition equation.

However, this comes at the cost of model fit with $\bar{D}$ estimated to be substantially larger for the fixed coefficient models. The DIC is minimized for the time-varying FAVAR with two factors and this model is used in the analysis below.

\subsection{The Estimated Factors and Stochastic Volatility}

The top left panels of figure 2 plot the estimated factors and the associated $68 \%$ error bands. Factor 2 is highly correlated with inflation measures in our dataset with a correlation of over -0.9 with CPI inflation and other inflation measures such as the change in the consumption deflator and the GDP deflator. Factor 2 also displays a reasonable correlation with GDP growth of around 0.4. This suggests that this factor captures the evolution of inflation and real activity in our dataset. On the other hand Factor 1 is highly correlated with financial variables included in our dataset, with the highest correlation ( of 0.97) with the five year government bond yield.

The factors are quite precisely estimated with the volatility of the shocks to their transition equations estimated to be high during the 1970s and the 1980s. However this volatility

literature we require the time-varying transition equation of the FAVAR to be stable at each point in time. This constraint becomes very difficult to impose when the number of endogenous variables in equation 2 exceeds 4 . Note that this computational constraint also prevents us from considering lag lengths longer than 2 . 

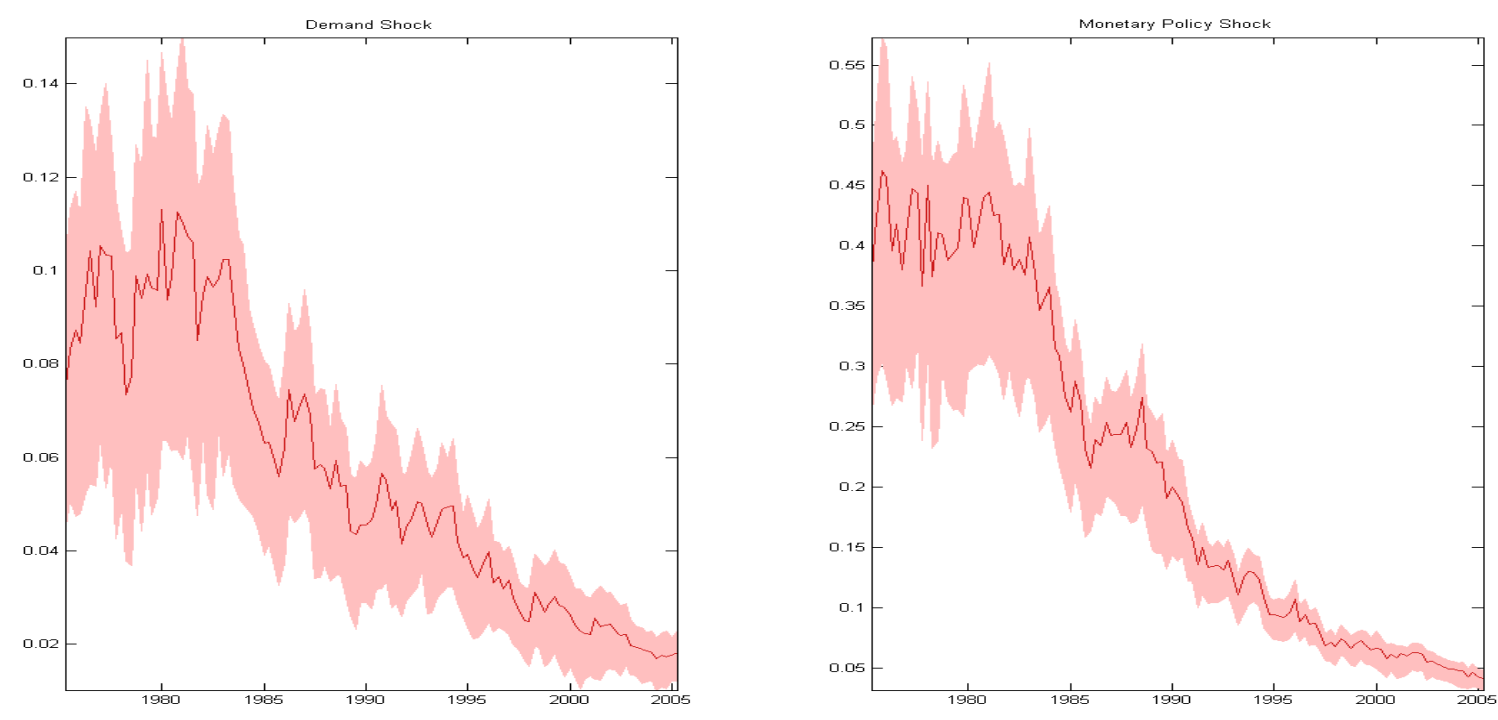

Figure 3: Volatility of the identified structural shocks.

declines substantially in the post-1985 period confirming the phenomenon referred to as the great moderation. The shock to the Bank rate equation was at its most volatile during the late 1970s. This volatility declined during the Thatcher dis-inflation of the early 1980s. The independence of the Bank of England saw a further decline in this volatility, with the variance close to zero over the period 1992-2005.

Figure 3 plots the estimated standard deviation of the structural shocks. This is calculated at each point in time as $\left(\bar{A}_{0, t}^{-1 \prime} \Omega_{t} \bar{A}_{0, t}^{-1}\right)^{1 / 2}$ where $\bar{A}_{0, t}$ is the $A_{0, t}$ matrix with the elements divided by the diagonal of this matrix. The estimates of the shock volatilities show a similar pattern - the volatility is high before the early 1990s with the inflation targeting period associated with the lowest variance.

\subsection{Impulse Response to a Monetary Policy Shock}

\subsubsection{Aggregate Series}

Figure 4 plots the cumulated response of (the quarterly growth rate of) real activity indicators to a monetary policy shock normalized to increase the Bank rate by 100 basis points in the contemporaneous period (the time-varying response of the Bank rate to this shock is shown in figure 5). The left panel of the figure plots the median response in each quarter. The middle two panels display the median response and the $68 \%$ confidence interval over the pre and post-1992 period. Note that the post-1992 period coincides with the adoption of inflation targeting in the United Kingdom and this is generally regarded as the most significant change (since the 1970s) to the monetary framework. Therefore, we present the average impulse response in these two periods as a way to assess if this change in the monetary framework was associated with a change in the transmission of structural shocks. To gauge the significance 

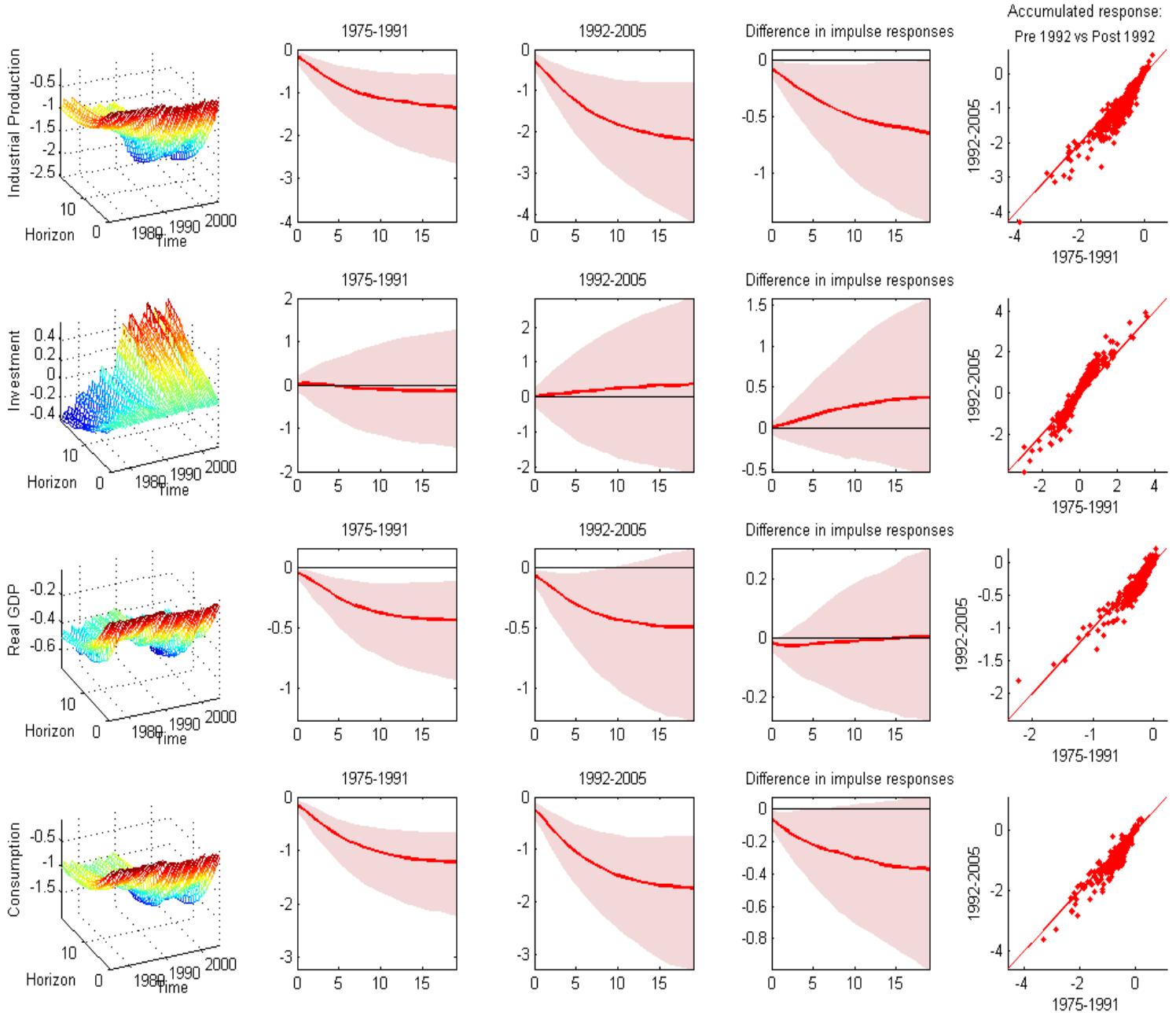

Figure 4: Impulse response of real activity to a monetary policy shock. The left panels present the time-varying median cumulated impulse response. The middle three panels show the average impulse response functions in the pre and post-1992 period and their difference, while the last panel shows the joint distribution of the cumulated response at the one year horizon in the pre and post-1992 period. 


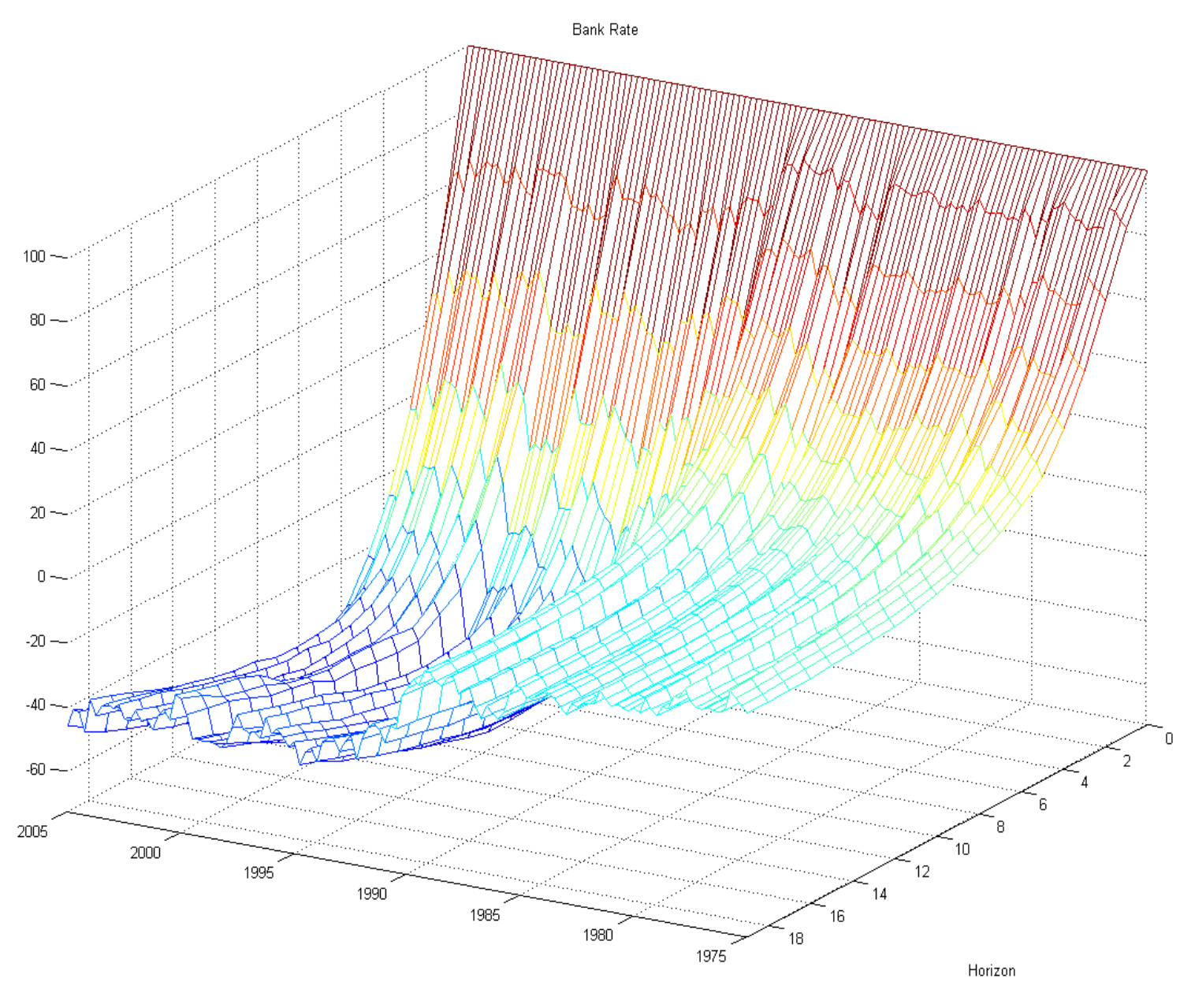

Time

Figure 5: Time-Varying impulse response of the bank rate to the monetary policy shock.

of any difference across these sub-periods, we present two additional pieces of information. The fourth panel of the figure plots the difference in the impulse response across the two sub-periods. The final panel plots the estimated joint distribution of the cumulated impulse response (at the 4 quarter horizon) pre and post-1992. Note that systematic differences result in the points not being distributed symmetrically around the 45 degree line. ${ }^{8}$

The contractionary policy shock reduces GDP by around $0.2 \%$ after one year in the pre-1992 period. The post-1992 response is very similar with the joint distribution concentrated on the 45-degree line The median response of industrial production and consumption is around $0.5 \%$ at the one year horizon in the pre-1992 period with some evidence that the magnitude of the response is somewhat larger in the post-1992 period. The response of consumption shows a similar pattern, although the change in the magnitude of the response in the post-1992 period is not statistically significant. The response of investment is imprecisely estimated.

The cumulated response of aggregate quarterly inflation measures to the monetary contrac-

${ }^{8}$ A similar method has been used, for example, in Cogley et al. (2010). 

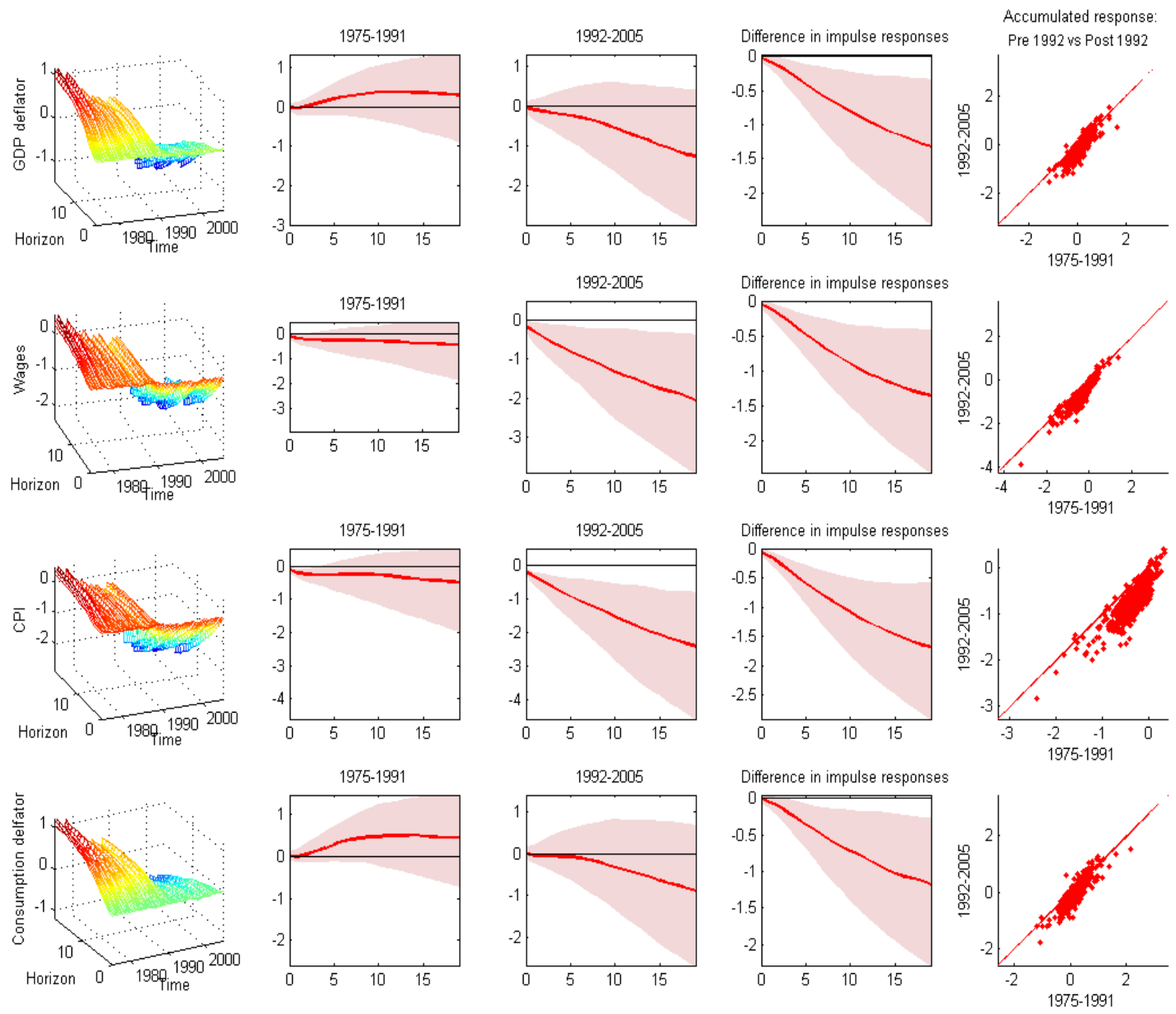

Figure 6: Impulse response of inflation to a monetary policy shock. The left panels present the time-varying median cumulated impulse response. The middle three panels show the average impulse response functions in the pre and post-1992 period and their difference, while the last panel shows the joint distribution of the cumulated response at the one year horizon in the pre and post-1992 period.

tion is presented in figure 6. In contrast to the response of real activity, the impulse response of inflation measures shows significant time-variation. The response of inflation measures is small and statistically insignificant in the pre-1992 period and large, negative and persistent during the inflation targeting period. The shift appears to be systematic, with the difference in the pre and post-1992 response significantly different from zero (and the joint distribution largely concentrated to the right of the 45 degree line).

Note that one aspect of these results is in contrast to those presented in Castelnuovo and Surico (2006) and Benati (2008) - i.e. our estimates are not characterized by a (statistically significant) price-puzzle during the 1970s as reported in these papers. This possibly reflects the fact that the identification of the monetary policy shock is more robust in our FAVAR model on account of it containing more information than the small scale models used in 

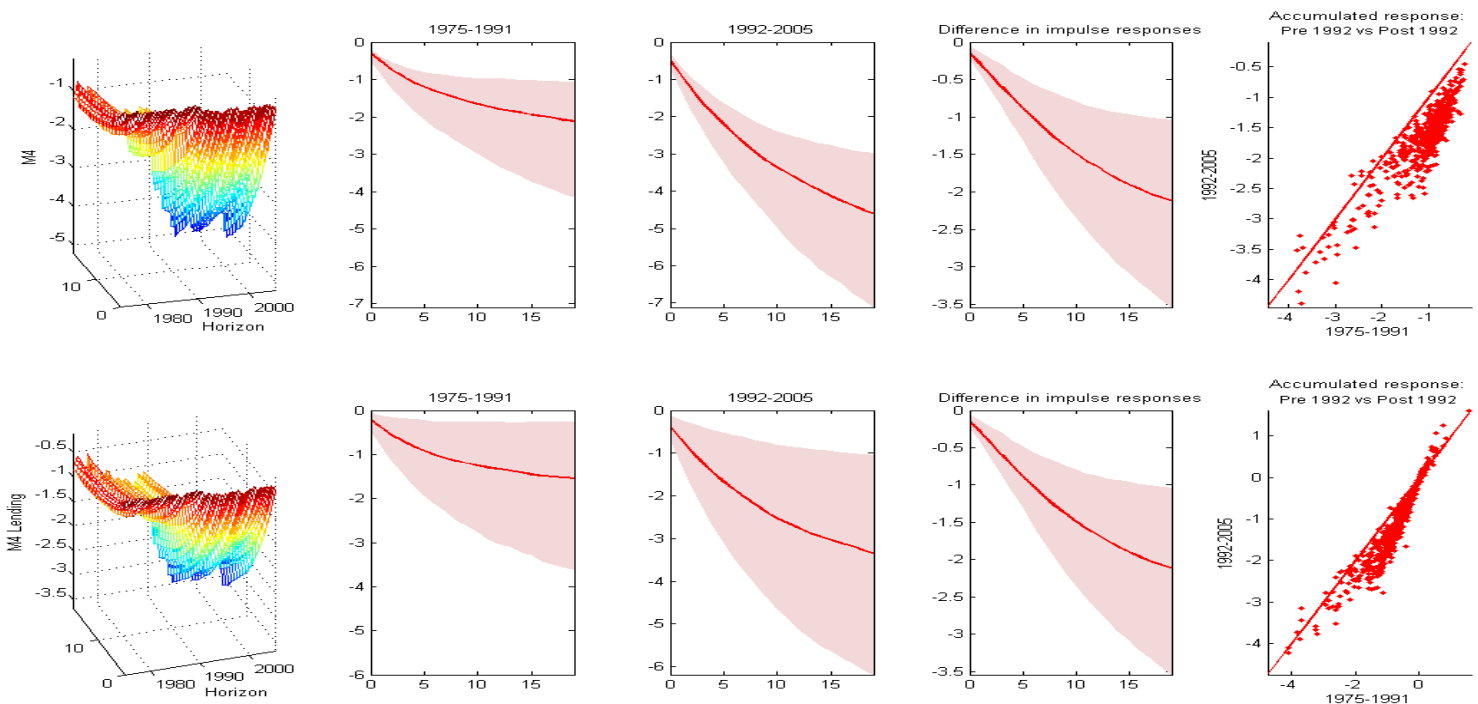

Figure 7: Impulse response of money to a monetary policy shock. The left panels present the time-varying median cumulated impulse response. The middle three panels show the average impulse response functions in the pre and post-1992 period and their difference, while the last panel shows the joint distribution of the cumulated response at the one year horizon in the pre and post-1992 period.

Castelnuovo and Surico (2006). However, as in Castelnuovo and Surico (2006) and Benati (2008) the price response is more negative over a policy regime associated with a higher degree of activism in response to inflation. Castelnuovo and Surico (2006) argue that this change in the response of inflation, reflects an underlying change in the monetary authorities' response to inflation, with higher activism consistent with a stronger negative response and an absence of the price puzzle. The increase in the magnitude of the response during the inflation targeting period is consistent with those arguments.

Figure 7 presents the response of broad money (M4 aggregate) and credit (M4 lending) growth to a monetary contraction. The estimates display a very similar pattern to those presented for inflation above. Generally, the (negative) response of M4 and M4 lending growth is stronger and more persistent in the post-1992 period, which is in line with the results reported in Benati (2008). A potential rationale for the 'liquidity puzzle' of the 70s and apparent instability of short-run money demand documented in figure 7 is developed in the theoretical paper of Alvarez and Lippi (2009).

The cumulated response of some key asset prices is shown in figure 8. The response of house prices shows little change over time with a decline of around $2 \%$ over the sample period. The FTSE reaction is somewhat stronger in the post-1992 period. Similarly, the NEER responds more to the policy shock in the post-1992 period. The response of the 10 year government bond yield shows the largest variation. In the pre-1992 period the cumulated fall in the yield is less than 1000 basis points in response to the policy shock (this corresponds to a 10 percentage point change). In the post-1992 period the magnitude almost doubles at the two year horizon with the joint distribution in the final column of the figure concentrated 

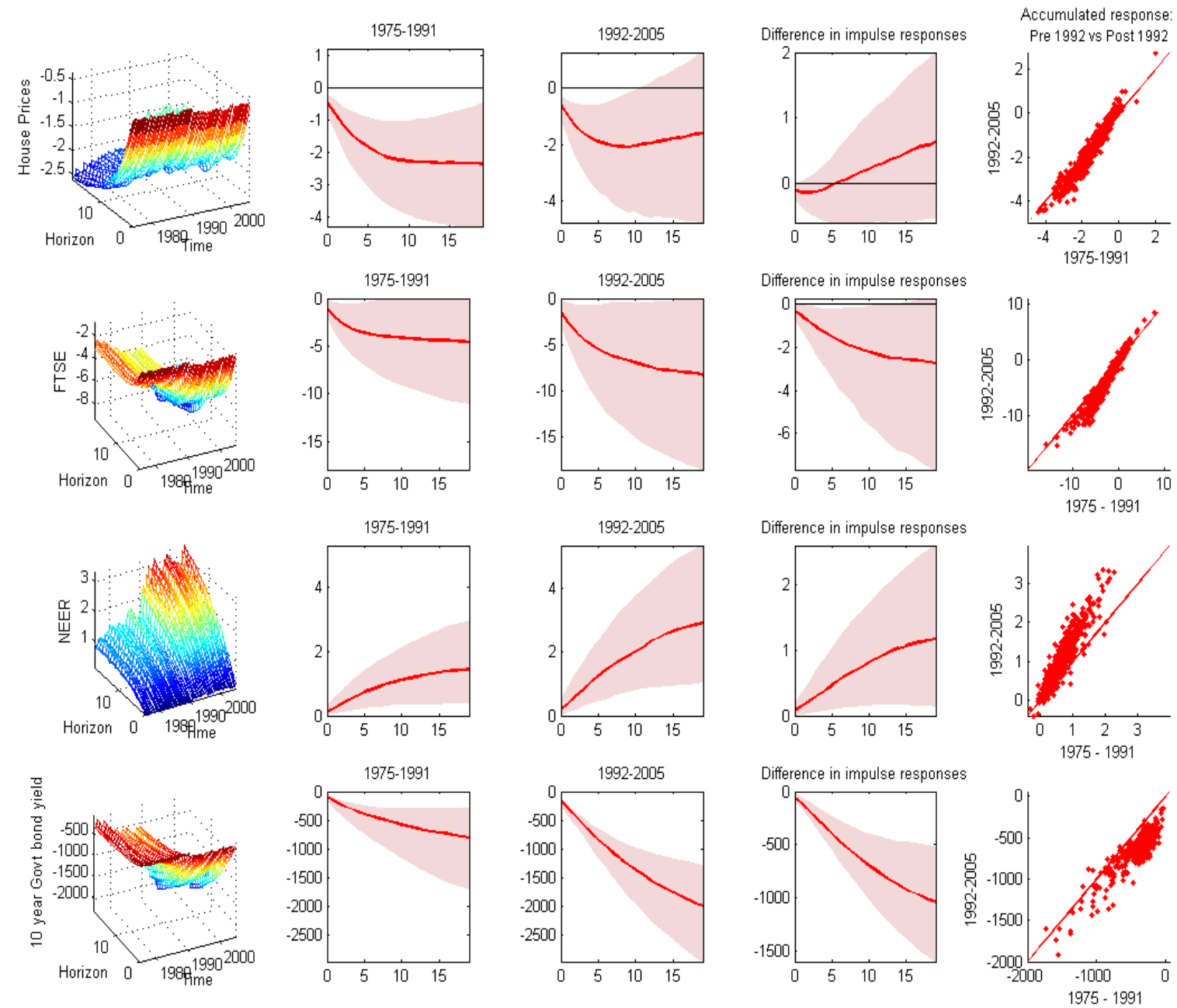

Figure 8: Impulse response of asset prices to a monetary policy shock. The left panels present the time-varying median cumulated impulse response. The middle three panels show the average impulse response functions in the pre and post-1992 period and the difference, while the last panel shows the joint distribution of the cumulated response at the one year horizon in the pre and post-1992 period.

to the right of the 45-degree line. This may reflect the fact that monetary policy was more credible during the inflation targeting period resulting in a larger response of inflation expectations implicitly reflected in the long term government bond yield. Note that a similar result is reported by Bianchi et al. (2009) who use a VAR model with yield curve factors to characterize yield curve dynamics.

\subsubsection{Response of the Components of the Consumption Deflator}

Our panel dataset comprises around 140 components of the consumption deflator. As in Boivin et al. (2009) our methodology allows us to derive the response of each of these series to a monetary policy shock. Moreover, we are also able to examine how the distribution of consumption deflator responses (across expenditure categories) has evolved over time. 

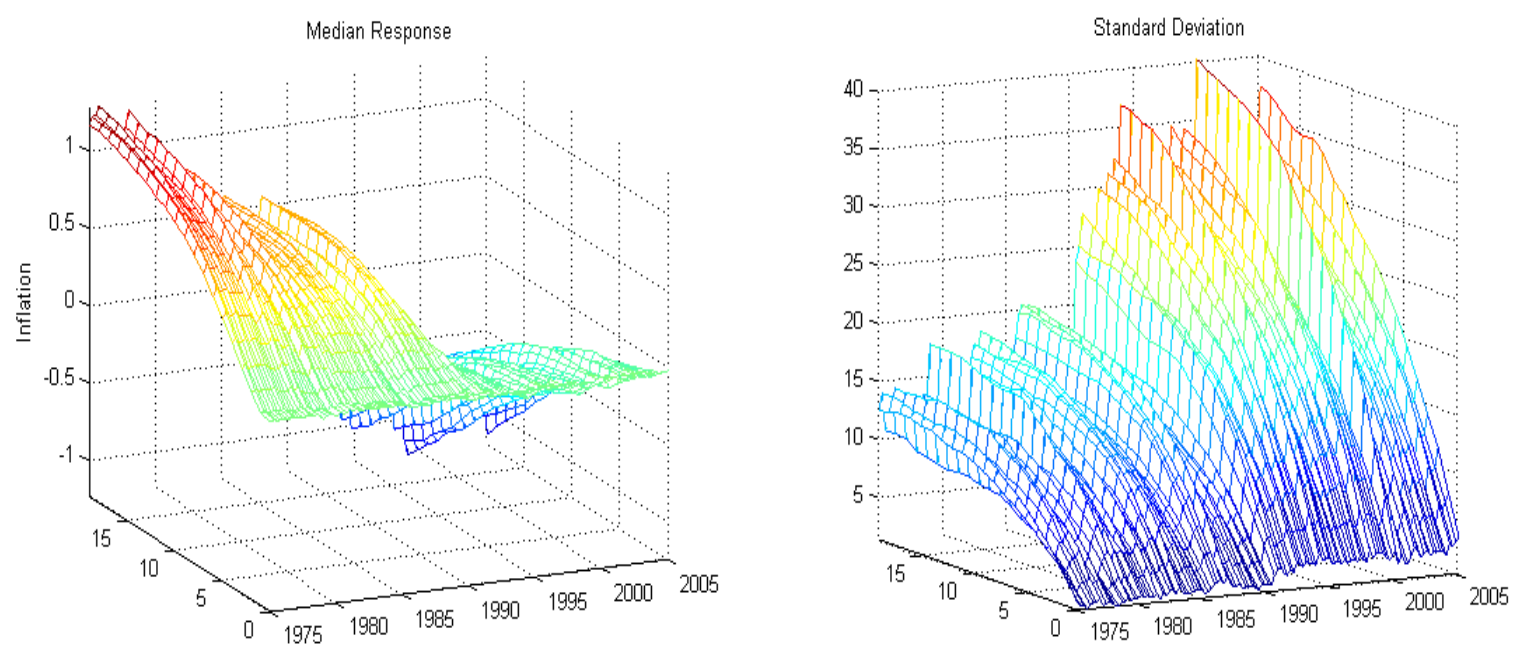

Figure 9: Changes in the distribution of the consumption deflator across time.

Figure 9 tracks the evolution of cross-sectional characteristics of the price level. The top left panel shows the evolution of the median response of the consumption deflator, which has clearly undergone a marked change. More specifically, in the pre-1992 period, although the price level initially falls in reaction to the monetary contraction, the fall is short-lived with the response becoming positive at longer horizons. This is in contrast to the post-1992 estimates where the median price level declines significantly. These results again point to the possible role of the changing monetary regime (see Castelnuovo and Surico (2006)).

Notably, the change in the median of the distribution is also associated with an increase in dispersion with the standard deviation (at longer horizons) higher during the 1990s. This means that although the median response is strongly negative in the current period, prices are more dispersed 20 quarters after the shock than during the 1980s. There is little systematic change in the skewness of the estimated distribution (not reported).

\subsubsection{Impulse Response to Demand Shocks}

Figure 10 shows the cumulated response of selected variables to the identified demand shock. The shock is normalized to increase GDP growth by $1 \%$ (in the initial period) at all dates in the sample. The cumulated response of industrial production shows little change across the sample period. On the other hand, the cumulated response of CPI inflation to the demand shock does change significantly. In particular, the median response of inflation in the post 1992 period is about half the magnitude of the pre-1992 response. Again, this could be related to changes in the monetary regime with inflation expectations possibly more firmly anchored under inflation targeting. Note that similar results for the US are reported in Leduc et al. (2007).

The pattern of the median response for money growth is similar to the results obtained for inflation. Finally, the post-1992 response of the long term government bond yield is smaller 

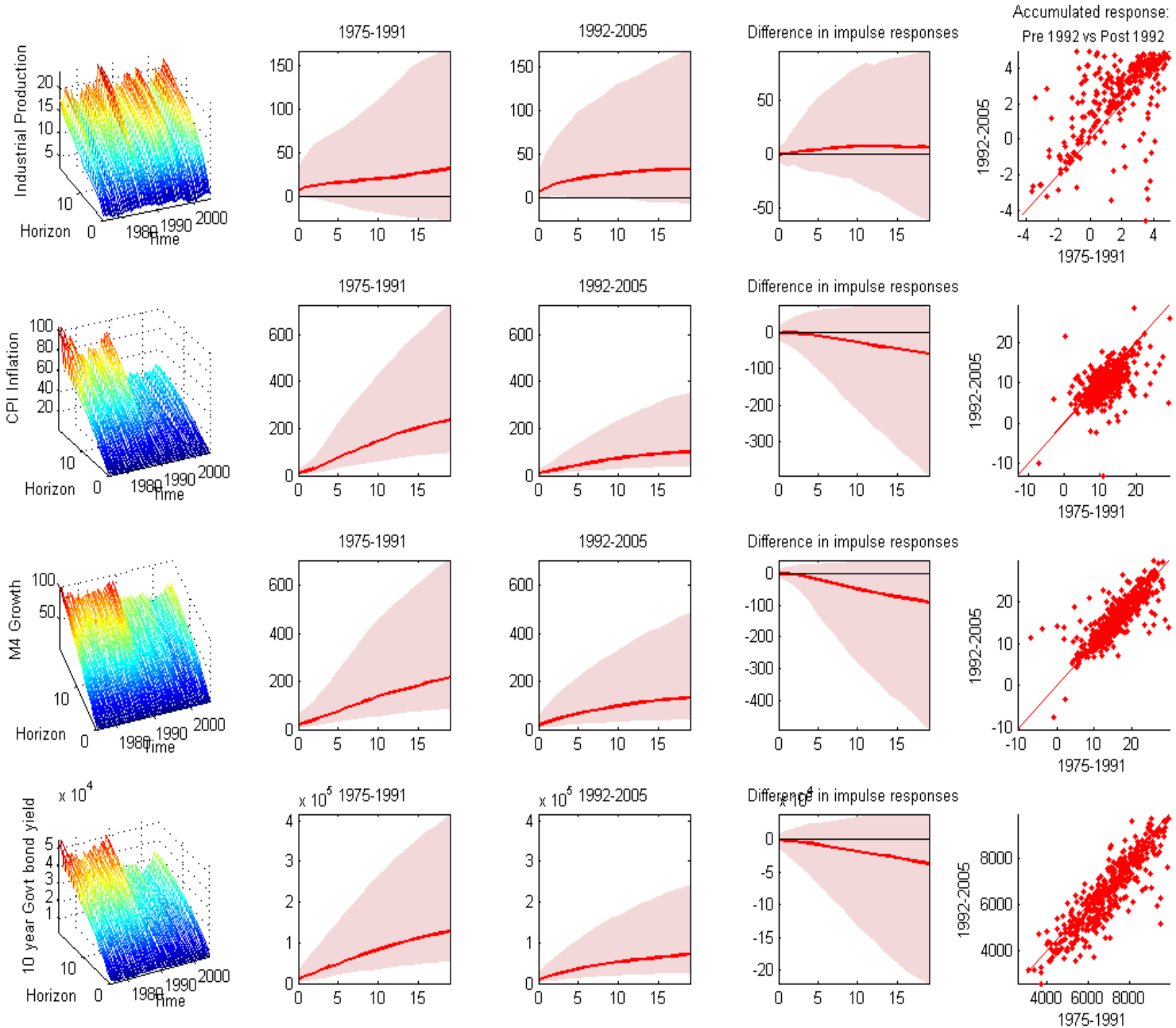

Figure 10: Impulse response to a demand shock. The left panels present the time-varying median cumulated impulse response. The middle three panels show the average impulse response functions in the pre and post-1992 period and their difference, while the last panel shows the joint distribution of the cumulated response at the one year horizon in the pre and post-1992 period. 

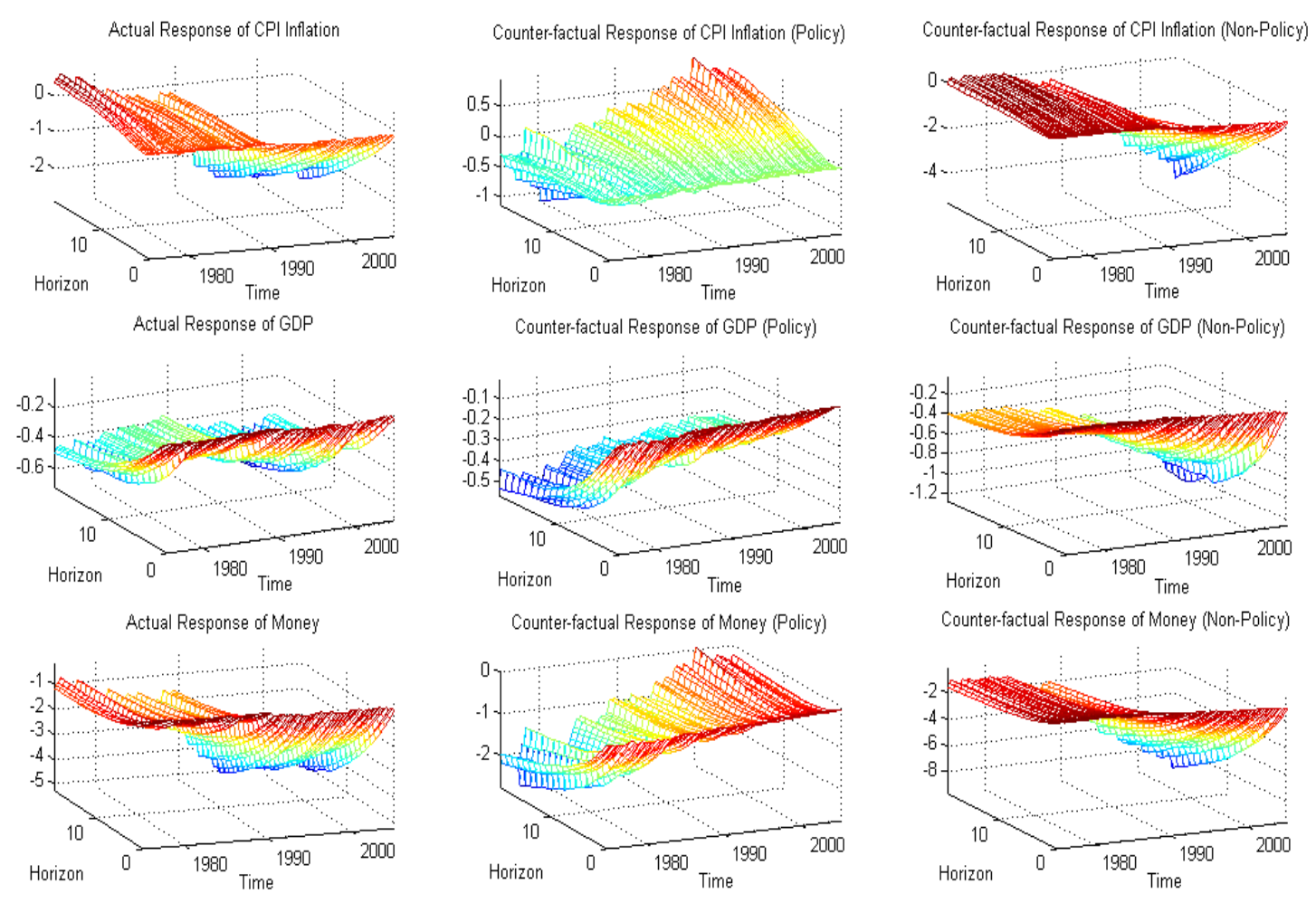

Counter-factual Response of Money (Non-Policy)

Actual Response of 10 year Govt bond yield

Counter-factual Response of 10 year Gont bond yield (Policy) Counter-factual Response of 10 year Gout bond yield (Non-Policy)
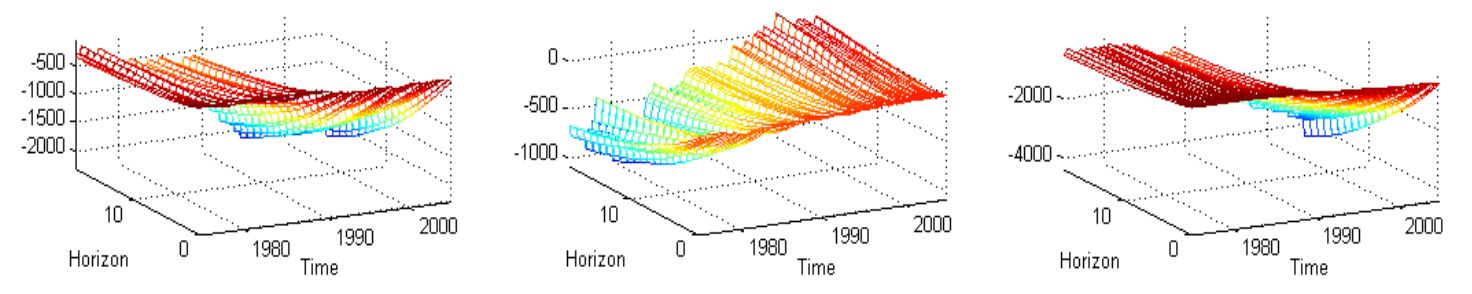

Figure 11: Impulse response to a monetary policy shock: actual and counterfactual.

than during the earlier period, again possibly reflecting the impact of the new monetary regime in anchoring inflation expectations.

\subsubsection{A Counterfactual Experiment to Assess the Role of Monetary Policy}

The estimated impulse response function reported above show significant time-variation in the responses of several key variables. The timing of these changes coincides with the onset of inflation targeting in the early 1990s and provides some prima facie evidence for the role played by policy. However, in order to explore this issue further, we use the estimated TVP-FAVAR to carry out a simple counterfactual experiment which aims to highlight the role of changes in the policy equation in driving the observed IRF shifts. The experiment involves the following steps: (a) denote the pre-1992 period sample1 and the post-1992 period sample2. For each Gibbs sampling replication we draw randomly from the lagged and contemporaneous coefficients and volatility associated with the transition equation of the model (equation 2) in sample 1. (b) we then consider two counterfactual paths for the 
parameters of equation 2. In the first case the elements of the interest rate equation are fixed at all time periods at the value of the corresponding parameters drawn in step (a). In the second case, the elements of the non-interest rate equations are fixed at those drawn from sample 1. (c) using these counterfactual parameters we estimate the impulse response of key variables at each point in time. The aim is to compare these counterfactual impulse response functions with the actual estimates. If changes in the parameters of the FAVAR policy rule are important then the impulse response functions estimated under case 1 in step b should not be characterized by the shifts across time evident in the actual estimated responses. Similarly, if the change in the parameters of the non-policy block of the FAVAR is important, then the counter factual impulse responses under case 2 should have have a different time-path than the actual estimates. ${ }^{9}$

Figure 11 shows the main results. The left column of the figure shows the actual estimated (cumulated) response of inflation, GDP growth, M4 and the 10 year government bond yield. The middle panel shows the estimated response under the assumption that the parameters of the FAVAR policy rule are fixed at values prevailing in the pre-1992 period. The final column shows the estimated response under the scenario that the parameters of the nonpolicy equations are fixed at values prevailing in the pre-1992 period. It is immediately clear from the second column of the figure that once the policy rule is constrained at pre-1992 values, the changes seen in the magnitude of actual impulse responses post-1992 disappear. In particular, the counterfactual response of inflation, money and the bond yield does not increase in magnitude over the inflation targeting period which is in sharp contrast to the actual estimates. Note from the third column that this is not the case when the non-policy block of the FAVAR is constrained with the estimated responses showing a pattern very similar to the actual estimates. These results support the conclusion that the reported changes in impulse response functions are largely driven by changes in the parameters of the FAVAR policy rule.

Figure 12 provides further evidence along these lines. The figure shows the moments of the distribution of the impulse response of the consumption deflator (to a monetary policy shock) estimated under the counterfactual scenario that the parameters of the FAVAR policy rule are fixed at values prevailing in the pre-1992 period. In contrast to the estimates shown in figure 9 , there is no shift in the median or the standard deviation of the distribution in the post-1992 period.

\section{Forecast Error Variance Decomposition}

In order to assess the relative importance of identified structural shocks, we calculate the time-varying forecast error variance decomposition. Figure 13 shows the median decompo-

\footnotetext{
${ }^{9}$ Notably, this experiment is not immune to the Lucas critique as we are unable to take into account the expectation effects of the assumed parameter changes.
} 

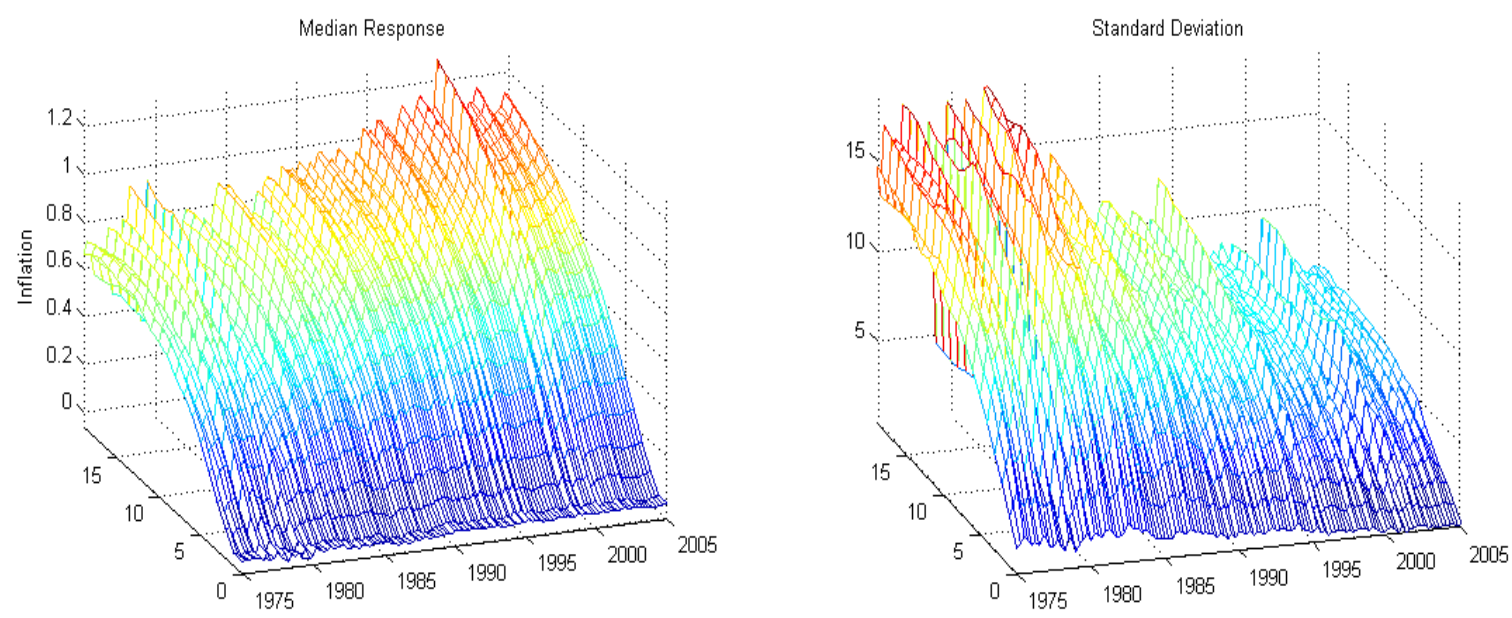

Figure 12: Changes in the distribution of the consumption deflator across time (counterfactual estimates).

sition for real activity indicators. Note that the $\mathrm{X}$-axis of each panel represents the timeperiods, the $\mathrm{Y}$-axis is the horizon in quarters while the Z-axis is the contribution to the forecast error variance. The monetary policy shock makes an important contribution to real activity indicators during the 1980s and the 1990s. The demand shock is less important on average but contributes around 20\% during the mid 1980s and the end of the sample period.

For inflation indicators (see figure 14) the demand shock contributes the most in the preinflation targeting period, (especially the 1980s) explaining about $30 \%$ to $40 \%$ of the forecast error variance of inflation indicators. Over the inflation targeting period, the contribution of this shock is less than $10 \%$. In contrast, the monetary policy shock appears to contribute more to inflation measures during the mid-1980s and the early 1990s.

Figure 15 plots the time-varying variance decomposition for money and credit growth. It is interesting to note that the contribution of monetary policy shocks increases substantially after 1990 rising to around $60 \%$. In contrast, demand shocks are more important during the 1970s and 1980s.

The monetary policy shock appears to be more important in terms of explaining the forecast error variance of the nominal exchange rate and the 10 year government bond yield after the 1990s (see figure 16). This shock explains about $60 \%$ of the forecast error variance of house prices and the FTSE during the 1980s and the 1990s. In contrast, the contribution of the demand shock to these asset prices is higher in the pre-1992 period, especially for house prices and the government bond yield. 

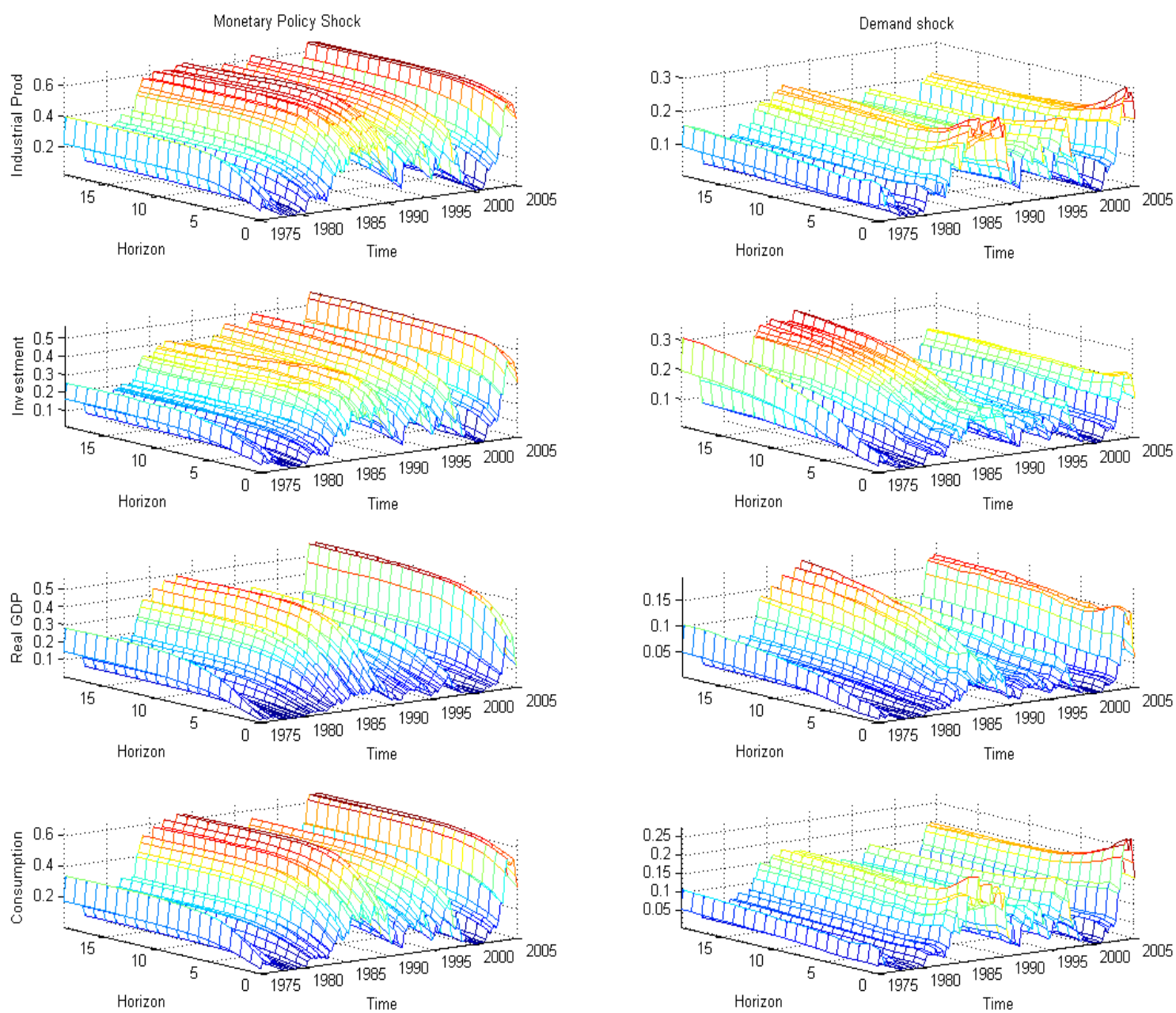

Figure 13: Forecast error variance decomposition of real activity indicators. 

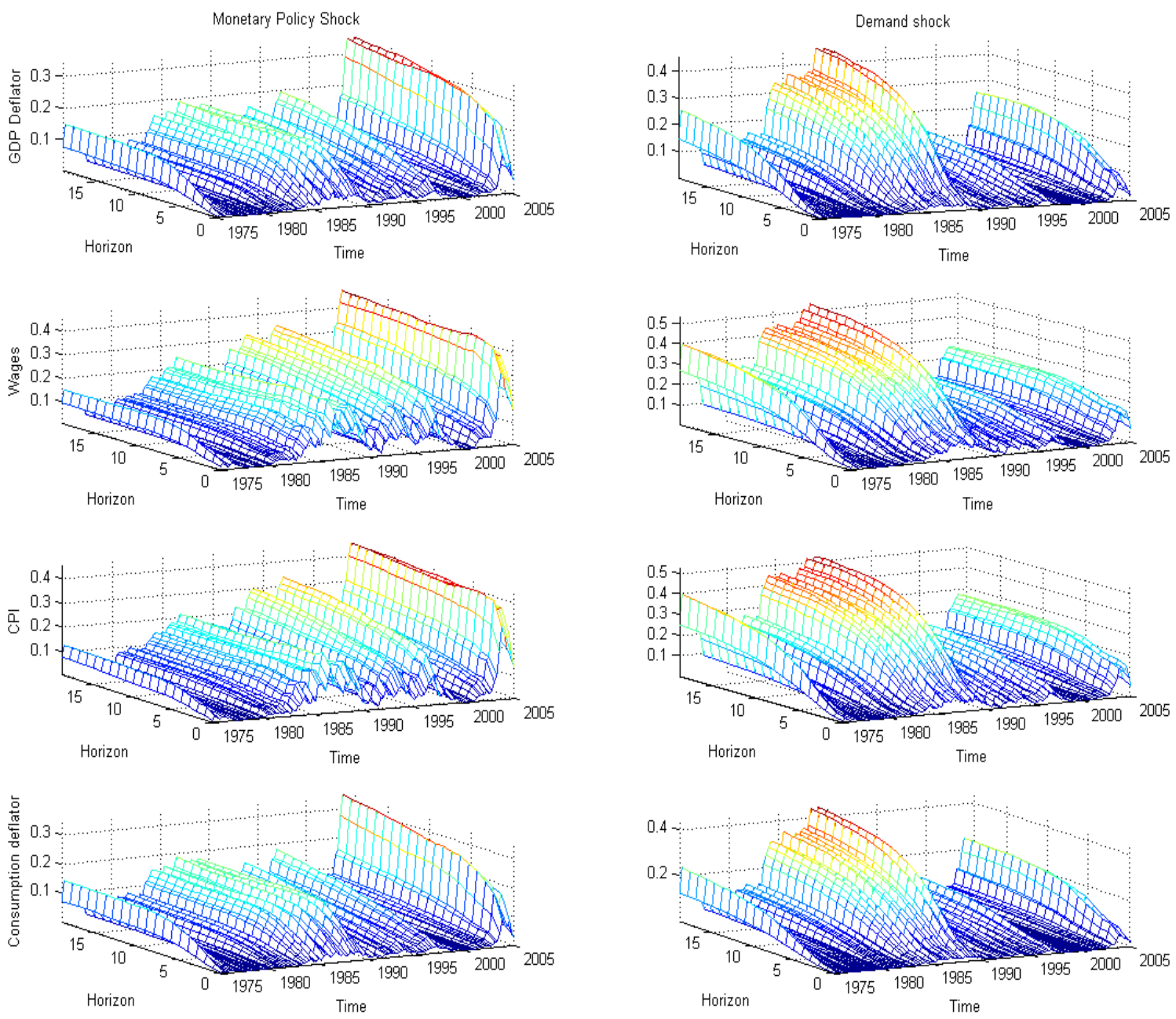

Figure 14: Forecast error variance decomposition of inflation measures. 

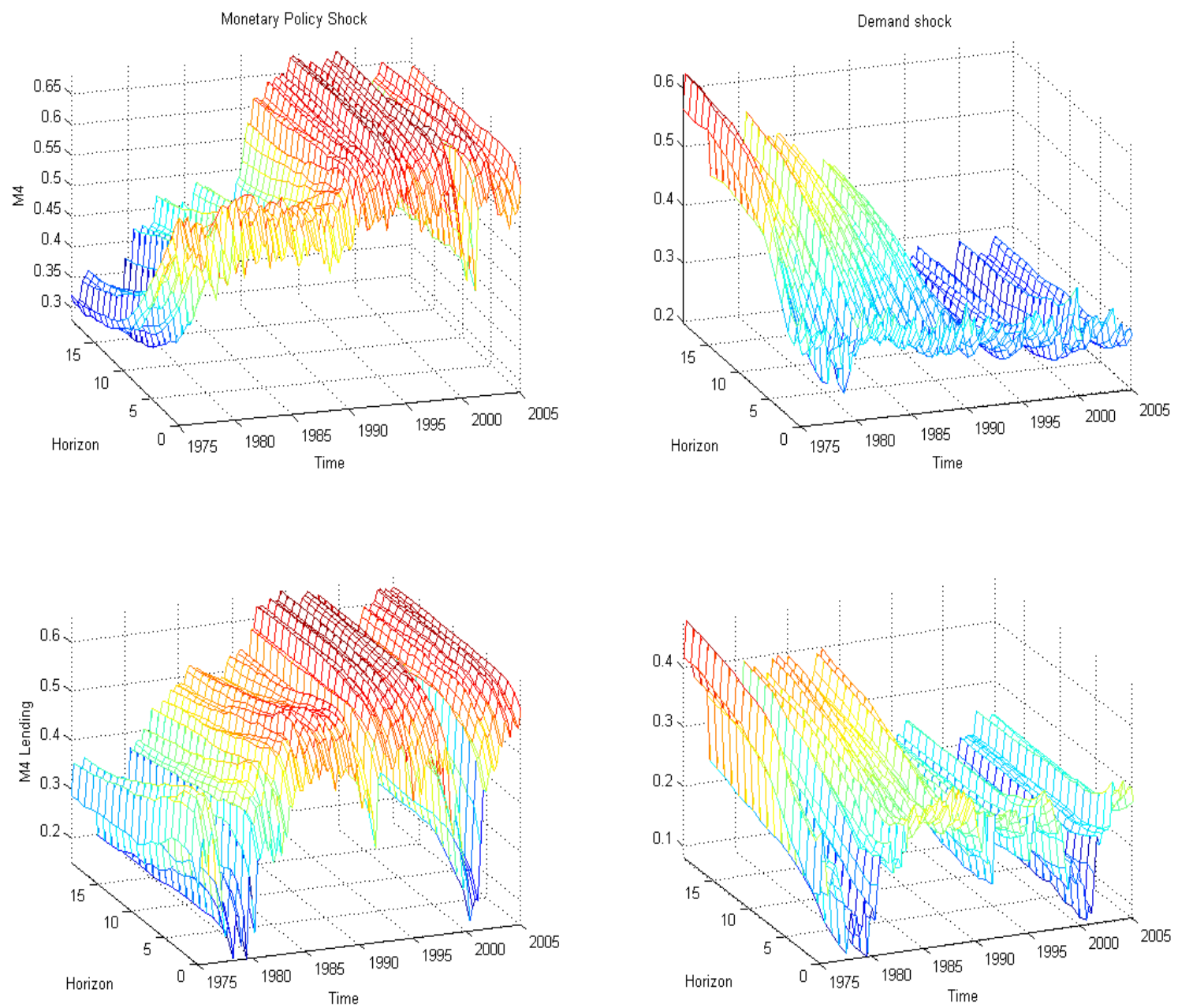

Figure 15: Forecast error variance decomposition of money supply measures. 

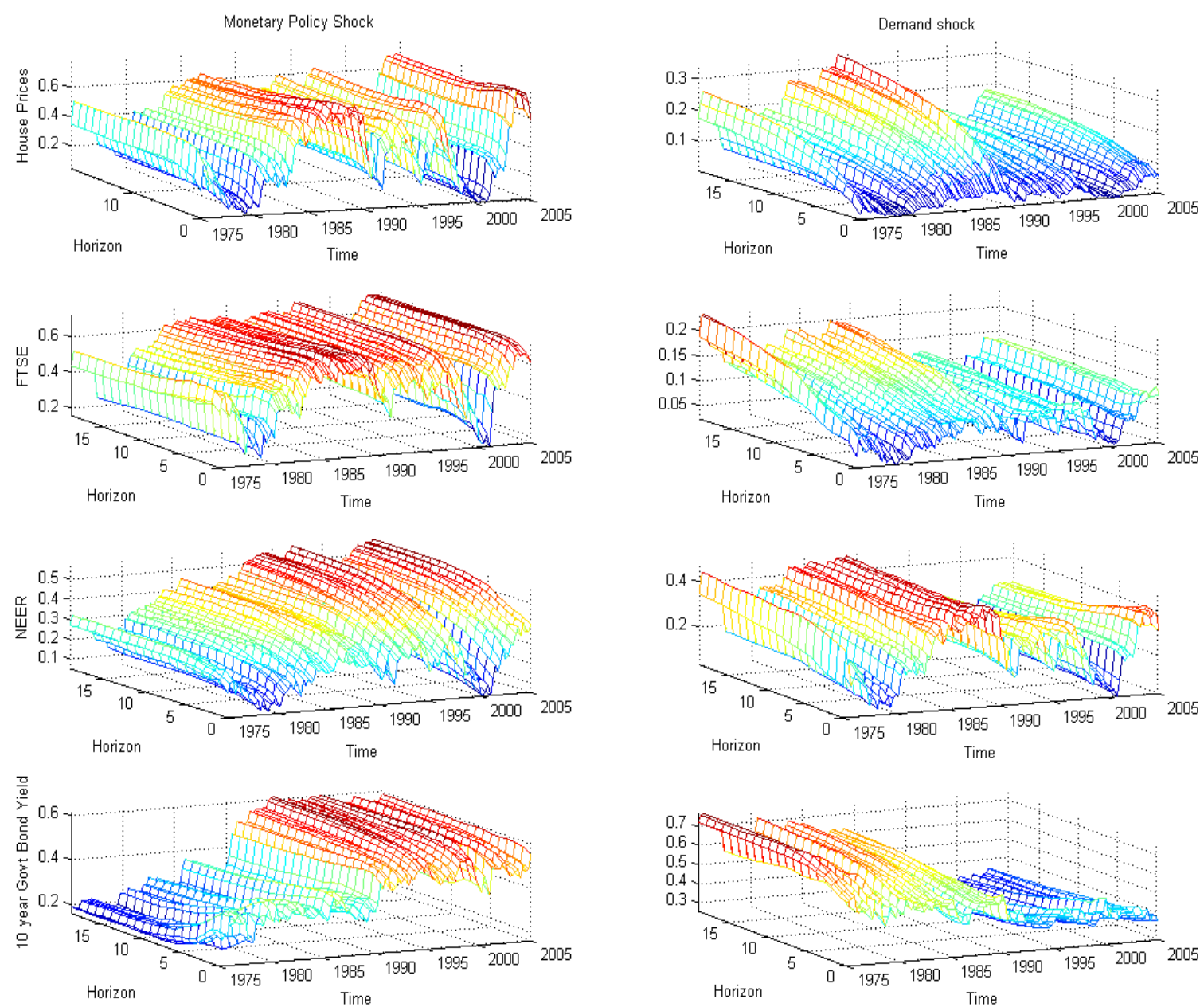

Figure 16: Forecast error variance decomposition of asset prices. 


\section{Conclusions}

Our aim in this paper was to empirically study the evolving transmission of monetary policy and demand shocks in the UK. To this end, we estimated a novel, factor-augmented VAR with time-varying coefficients and shock volatility which made possible the simultaneous analysis of changing impulse responses of a large set of aggregate macroeconomic variables, disaggregated prices and quantities.

We documented that the impulse responses to UK monetary policy, and demand shocks have changed visibly over the last thirty years. Both the impulse responses and variance decompositions show that around the beginning of the nineties monetary policy shocks started having a bigger impact on prices and began contributing more to overall volatility. We also present evidence of changes in the response of asset prices and components of the consumption deflator - with the median reaction of the latter to contractionary policy shocks becoming more negative. Counterfactual experiments show that these changes are linked to changes in the parameters of the policy rule in our empirical model.

Our results suggest that time-variation should be taken seriously, which has clear implications for structural economic models. They also highlight a number of interesting links between the evolution of real and nominal variables and asset prices. While attempting to account for these links and for the way they change over time in a stochastic, dynamic, generalequilibrium framework is beyond the scope of this paper, we believe that it would be a worthwhile extension. 


\section{APPENDIX}

\section{A Priors and Estimation}

Our time-varying FAVAR model consists of the following equations

$$
\begin{gathered}
\left(\begin{array}{c}
X_{1, t} \\
\cdot \\
\cdot \\
X_{N, t} \\
R_{t}
\end{array}\right)=\left(\begin{array}{ccc}
\Lambda^{11} & \Lambda^{21} & \Psi^{11} \\
\cdot & \cdot & \cdot \\
\dot{1 N} & \dot{\Lambda^{2 N}} & \Psi^{1 N} \\
0 & 0 & 1
\end{array}\right)\left(\begin{array}{c}
F_{t}^{1} \\
F_{t}^{2} \\
R_{t}
\end{array}\right)+\left(\begin{array}{c}
e_{1 t} \\
\cdot \\
\cdot \\
e_{N t} \\
0
\end{array}\right) \\
Z_{t}=\sum_{l=1}^{L} \phi_{l, t} Z_{t-l}+v_{t}
\end{gathered}
$$

with $Z_{t}=\left\{F_{t}^{1}, F_{t}^{2}, R_{t}\right\}, L$ fixed at 2 and the coefficients $\phi$ assumed to evolve according to

$$
\phi_{t}=\phi_{t-1}+\eta_{t}
$$

The covariance matrix of the innovations $v_{t}$ is factored as

$$
\operatorname{VAR}\left(v_{t}\right) \equiv \Omega_{t}=A_{t}^{-1} H_{t}\left(A_{t}^{-1}\right)^{\prime}
$$

where the time-varying matrices $H_{t}$ and $A_{t}$ are given by

$$
H_{t} \equiv\left[\begin{array}{ccc}
h_{1, t} & 0 & 0 \\
0 & h_{2, t} & 0 \\
0 & 0 & h_{3, t}
\end{array}\right] \quad A_{t} \equiv\left[\begin{array}{ccc}
1 & 0 & 0 \\
\alpha_{21, t} & 1 & 0 \\
\alpha_{31, t} & \alpha_{32, t} & 1
\end{array}\right]
$$

with the $h_{i, t}$ evolving as geometric random walks

$$
\ln h_{i, t}=\ln h_{i, t-1}+\nu_{t} .
$$

Following Primiceri (2005) we postulate that the non-zero and non-one elements of the matrix $A_{t}$ evolve as driftless random walks

$$
\alpha_{t}=\alpha_{t-1}+\tau_{t}
$$

and we also assume that $\left[e_{t}^{\prime}, v_{t}^{\prime}, \eta_{t}^{\prime}, \tau_{t}^{\prime}, \nu_{t}^{\prime}\right]^{\prime} \sim N(0, V)$ with

$$
V=\left[\begin{array}{ccccc}
R & 0 & 0 & 0 & 0 \\
0 & \Omega_{t} & 0 & 0 & 0 \\
0 & 0 & Q & 0 & 0 \\
0 & 0 & 0 & S & 0 \\
0 & 0 & 0 & 0 & G
\end{array}\right] \text { and } G=\left[\begin{array}{cccc}
\sigma_{1}^{2} & 0 & 0 & 0 \\
0 & \sigma_{2}^{2} & 0 & 0 \\
0 & 0 & \sigma_{3}^{2} & 0 \\
0 & 0 & 0 & \sigma_{4}^{2}
\end{array}\right]
$$

Bernanke et al. (2005) show that identification of the FAVAR model given by equations 6 and 7 requires putting some (in our case contemporaneous) restrictions on the matrix of factor loadings. Following their example we assume that the top $J \times J$ block of $\Lambda$ is an identity matrix and the top $J \times M$ block of $\Psi$ equals zero. The model is then estimated using a Gibbs sampling algorithm with the conditional prior and posterior distributions described below. 


\section{A.1 Prior Distributions and Starting Values}

\section{A.1.1 Factors and Factor Loadings}

Following Bernanke et al. (2005) we center our prior on the factors (and obtain starting values) by using a principal components (PC) estimator applied to each $X_{i, t}$. In order to reflect the uncertainty surrounding the choice of starting values, a large prior covariance of the states $\left(P_{0 / 0}\right)$ is assumed.

Starting values for the factor loadings are also obtained from the PC estimator after imposing the above restrictions. The priors on the diagonal elements of $R$ are assumed to be inverse gamma

$$
R_{i i} \sim \operatorname{IG}\left(R_{0}, V_{0}\right) .
$$

where $R_{0}=0.01$ and $V_{0}=1$ denote the prior scale parameter and the prior degrees of freedom respectively.

\section{A.1.2 VAR Coefficients}

The prior for the VAR coefficients is obtained via a fixed coefficients VAR model estimated over the first 10 years of the sample using the principal component estimates of the factors. Accordingly, $\phi_{0}$ is equal to

$$
\phi_{0} \sim N\left(\hat{\phi}^{O L S}, V\right)
$$

where $V$ equals 0.0001 times OLS estimates of the main diagonal of $\operatorname{var}\left(\hat{\phi}^{O L S}\right)$.

\section{A.1.3 Elements of $H_{t}$}

Let $\hat{v}^{\text {ols }}$ denote the OLS estimate of the VAR covariance matrix estimated on the pre-sample data described above. The prior for the diagonal elements of the VAR covariance matrix (see equation 9) is as follows

$$
\ln h_{0} \sim N\left(\ln \mu_{0}, I_{N}\right)
$$

where $\mu_{0}$ are the diagonal elements of the Cholesky decomposition of $\hat{v}^{o l s}$.

\section{A.1.4 Elements of $A_{t}$}

The prior for the off-diagonal elements of $A_{t}$ is

$$
A_{0} \sim N\left(\hat{a}^{o l s}, V\left(\hat{a}^{o l s}\right)\right)
$$

where $\hat{a}^{\text {ols }}$ are the off-diagonal elements of $\hat{v}^{\text {ols }}$, with each row scaled by the corresponding element on the diagonal. The matrix $V\left(\hat{a}^{\text {ols }}\right)$ is assumed to be diagonal with the diagonal elements set equal to 10 times the absolute value of the corresponding element of $\hat{a}^{\text {ols }}$.

\section{A.1.5 Hyperparameters}

The prior on $Q$ is assumed to be inverse Wishart

$$
Q_{0} \sim I W\left(\bar{Q}_{0}, T_{0}\right)
$$


where $\bar{Q}_{0}$ is assumed to be $\operatorname{var}\left(\hat{\phi}^{O L S}\right) \times 10^{-4} \times 3.5$ and $T_{0}$ is the length of the sample used for calibration. The prior distribution for the blocks of $S$ is also inverse Wishart

$$
S_{i, 0} \sim I W\left(\bar{S}_{i}, K_{i}\right)
$$

where $i$ indexes the blocks of $S$ and $\bar{S}_{i}$ is calibrated using $\hat{a}^{\text {ols }}$. Specifically, $\bar{S}_{i}$ is a diagonal matrix with the relevant elements of $\hat{a}^{\text {ols }}$ multiplied by $10^{-3}$. Finally, following Cogley and Sargent (2005), we postulate an inverse-gamma distribution for the elements of $G$

$$
\sigma_{i}^{2} \sim I G\left(\frac{10^{-4}}{2}, \frac{1}{2}\right)
$$

\section{A.2 Simulating the Posterior Distributions}

\section{A.2.1 Factors and Factor Loadings}

This closely follows Bernanke et al. (2005). Details can also be found in Kim and Nelson (1999).

Factors The distribution of the factors $F_{t}$ is linear and Gaussian

$$
\begin{aligned}
& F_{T} \backslash X_{i, t}, R_{t}, \Xi \sim N\left(F_{T \backslash T}, P_{T \backslash T}\right) \\
& F_{t} \backslash F_{t+1}, X_{i, t}, R_{t}, \Xi \sim N\left(F_{t \backslash t+1, F_{t+1}}, P_{t \backslash t+1, F_{t+1}}\right)
\end{aligned}
$$

where $t=T-1, . ., 1$, the vector $\Xi$ holds all other FAVAR parameters and

$$
\begin{aligned}
F_{T \backslash T} & =E\left(F_{T} \backslash X_{i, t}, R_{t}, \Xi\right) \\
P_{T \backslash T} & =\operatorname{Cov}\left(F_{T} \backslash X_{i, t}, R_{t}, \Xi\right) \\
F_{t \backslash t+1, F_{t+1}} & =E\left(F_{t} \backslash X_{i, t}, R_{t}, \Xi, F_{t+1}\right) \\
P_{t \backslash t+1, F_{t+1}} & =\operatorname{Cov}\left(F_{t} \backslash X_{i, t}, R_{t}, \Xi, F_{t+1}\right) .
\end{aligned}
$$

In line with Carter and Kohn (1994) the simulation consists of several steps. First we use the Kalman filter to draw $F_{T \backslash T}$ and $P_{T \backslash T}$ and then proceed backwards in time using

$$
\begin{gathered}
F_{t \mid t+1}=F_{t \mid t}+P_{t \mid t} P_{t+1 \mid t}^{-1}\left(F_{t+1}-F_{t}\right) \\
P_{t \mid t+1}=P_{t \mid t}-P_{t \mid t} P_{t+1 \mid t}^{-1} P_{t \mid t} .
\end{gathered}
$$

If more than one lag of the factors appears in the VAR model, this procedure has to be modified to take account of the fact that the covariance matrix of the shocks to the transition equation (used in the filtering procedure described above) is singular. For details see Kim and Nelson (1999).

Elements of $R$ Following Bernanke et al. (2005) $R$ is a diagonal matrix. The diagonal elements $R_{i i}$ are drawn from the following inverse gamma distribution

$$
R_{i i} \sim I G\left(\bar{R}_{i i}, T+V_{0}\right)
$$


where

$$
\bar{R}_{i i}=\hat{e}_{i}^{\prime} \hat{e}_{i}+R_{0}
$$

with $\hat{e}_{i}$ denoting the residual $X_{i t}-\Gamma_{i} F_{j t}$ where $\Gamma_{i}=\Lambda_{i}$ or $\Gamma_{i}=\left[\Lambda_{i}, \Psi\right]$ for the appropriate equation.

Elements of $\Lambda$ and $\Psi$ Letting $\Gamma_{i}=\Lambda_{i}$ or $\Gamma_{i}=\left[\Lambda_{i}, \Psi\right]$ for the appropriate equation, the factor loadings are sampled from

$$
\Gamma_{i} \sim N\left(\bar{\Gamma}_{i}, R_{i i} \bar{M}_{i}^{-1}\right)
$$

where $\bar{\Gamma}_{i}=\bar{M}_{i}^{-1}\left(F_{i, t}^{\prime} F_{i, t}\right) \hat{\Gamma}_{i}, \bar{M}_{i}=\bar{M}_{0}+\left(F_{i, t}^{\prime} F_{i, t}\right)$ and $\hat{\Gamma}_{i}$ represents an OLS estimate and $\bar{M}_{0}=I$.

\section{A.2.2 Time-Varying VAR}

Given an estimate of the factors, the model becomes a VAR with drifting coefficients and covariances. This type of specification has become fairly standard in the literature and details on the posterior distributions can be found in a number of papers including Cogley and Sargent (2005), Cogley et al. (2005) and Primiceri (2005). Accordingly, we only provide a summary of the estimation algorithm - referring to the references above for further details.

The Gibbs sampler cycles through the following steps:

1. Given initial values for the factors, the VAR parameters and hyperparameters are simulated.

- As in the case of the unobserved factors the VAR coefficients $\phi_{t}$ and the offdiagonal elements of the covariance matrix $\alpha_{t}$ are simulated using the methods described in Carter and Kohn (1994). In particular, given a draw for $\phi_{t}$ the VAR model can be written as

$$
A_{t}^{\prime}\left(\tilde{Z}_{t}\right)=u_{t}
$$

where $\tilde{Z}_{t}=Z_{t}-\sum_{l=1}^{L} \phi_{l, t} Z_{t-l}=v_{t}$ and $V A R\left(u_{t}\right)=H_{t}$. This is a system of equations with time-varying coefficients and so, given a block diagonal form for $\operatorname{Var}\left(\tau_{t}\right)$, the standard methods for state space models can be applied.

- Following Cogley and Sargent (2005), the volatilities of the reduced form shocks $H_{t}$ are drawn using the date by date blocking scheme introduced in Jacquier et al. (2002).

- The hyperparameters are drawn from their respective distributions. Conditional on $Z_{t}, \phi_{l, t}, H_{t}$, and $A_{t}$, the innovations to $\phi_{l, t}, H_{t}$, and $A_{t}$ are observable, which allows us to draw the hyperparameters - the elements of $Q, S$, and the $\sigma_{i}^{2}$-from their respective distributions.

2. Given initial values for the factors, the factor loadings $\Lambda$ and $\Psi$ and the variances of the idiosyncratic components are drawn. 
- Given data on $R_{t}$ and $X_{i, t}$ standard results for regression models can be used and the coefficients and the variances are simulated from a normal and inverse gamma distribution.

3. Finally, the factors are simulated given all the other parameters.

- This is done in a straightforward way by employing the methods described in Bernanke et al. (2005) and Kim and Nelson (1999).

4. Go to step 1.

\section{A.3 Convergence}

We use 55,000 iterations in this MCMC algorithm discarding the first 45,000 as burn-in. The figure below shows the recursive means of the retained draws. These show limited fluctuations providing some evidence of convergence.
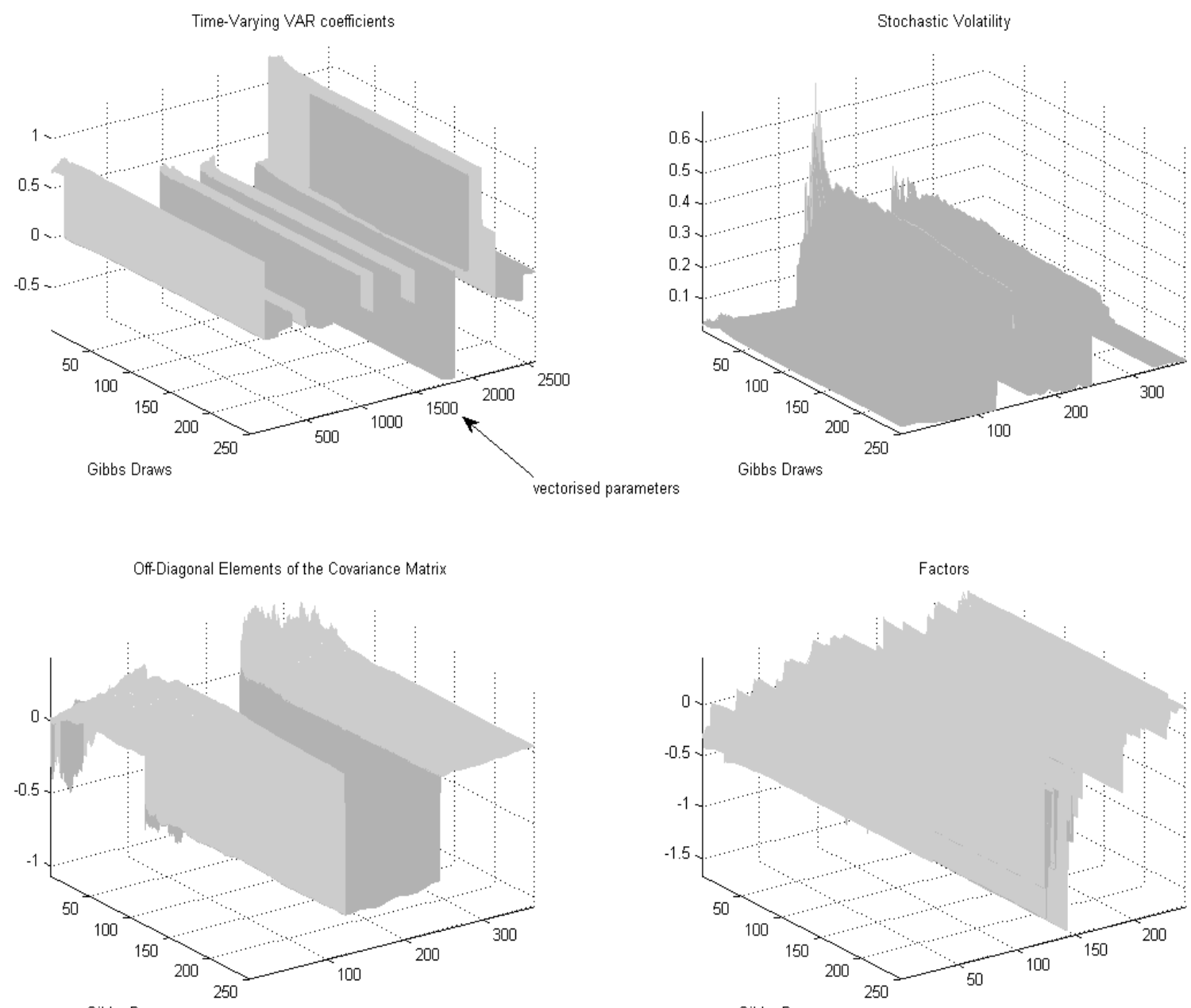

Gibbs Draws

Gibbs Draws

\section{A.4 Particle Filter to Evaluate the Likelihood for the TVP-FAVAR}

An excellent detailed description of particle filtering and its application to macroeconomic models can be found in Fernandez-Villaverde and Rubio-Ramirez (2008) and the references 
cited therein. Below we provide a brief description of the filter as applied to our FAVAR model.

Consider the distribution of the state variables (i.e. the time-varying coefficients, stochastic volatilities and the factors) in the Time-Varying FAVAR model denoted $\Phi_{t}$ conditional on information up to time $t$ (denoted by $z_{t}$ )

$$
f\left(\Phi_{t} \backslash z_{t}\right)=\frac{f\left(X_{t}, \Phi_{t} \backslash z_{t-1}\right)}{f\left(X_{t} \backslash z_{t-1}\right)}=\frac{f\left(X_{t} \backslash \Phi_{t}, z_{t-1}\right) \times f\left(\Phi_{t} \backslash z_{t-1}\right)}{f\left(X_{t} \backslash z_{t-1}\right)} .
$$

Equation 12 says that this density can be written as the ratio of the joint density of the data and the states $f\left(X_{t}, \Phi_{t} \backslash z_{t-1}\right)=f\left(X_{t} \backslash \Phi_{t}, z_{t-1}\right) \times f\left(\Phi_{t} \backslash z_{t-1}\right)$ and the likelihood function $f\left(X_{t} \backslash z_{t-1}\right)$ where the latter is defined as

$$
f\left(X_{t} \backslash z_{t-1}\right)=\int f\left(X_{t} \backslash \Phi_{t}, z_{t-1}\right) \times f\left(\Phi_{t} \backslash z_{t-1}\right) d \Phi_{t} .
$$

Note also that the conditional density $f\left(\Phi_{t} \backslash z_{t-1}\right)$ can be written as

$$
f\left(\Phi_{t} \backslash z_{t-1}\right)=\int f\left(\Phi_{t} \backslash \Phi_{t-1}\right) \times f\left(\Phi_{t-1} \backslash z_{t-1}\right) d \Phi_{t-1} .
$$

These equations suggest the following filtering algorithm to compute the likelihood function:

1. Given a starting value $f\left(\Phi_{0} \backslash z_{0}\right)$ calculate the predicted value of the state

$$
f\left(\Phi_{1} \backslash z_{0}\right)=\int f\left(\Phi_{1} \backslash \Phi_{0}\right) \times f\left(\Phi_{0} \backslash z_{0}\right) d \Phi_{0}
$$

2. Update the value of the state variables based on information contained in the data

$$
f\left(\Phi_{1} \backslash z_{1}\right)=\frac{f\left(X_{1} \backslash \Phi_{1}, z_{0}\right) \times f\left(\Phi_{1} \backslash z_{0}\right)}{f\left(X_{1} \backslash z_{0}\right)}
$$

where $f\left(X_{1} \backslash z_{0}\right)=\int f\left(X_{1} \backslash \Phi_{1}, z_{0}\right) \times f\left(\Phi_{1} \backslash z_{0}\right) d \Phi_{1}$ is the likelihood for observation 1 . By repeating these two steps for observations $t=1 \ldots T$ the likelihood function of the model can be calculated as $\ln l i k=\ln f\left(X_{1} \backslash z_{0}\right)+\ln f\left(X_{2} \backslash z_{1}\right)+\ldots \ln f\left(X_{T} \backslash z_{t-1}\right)$.

In general, this algorithm is inoperable because the integrals in the equations above are difficult to evaluate. The particle filter makes the algorithm feasible by using a MonteCarlo method to evaluate these integrals. In particular, the particle filter approximates the conditional distribution $f\left(\Phi_{1} \backslash z_{0}\right)$ via $M$ draws or particles using the transition equation of the FAVAR model. For each draw of the state variables the conditional likelihood $W^{m}=$ $f\left(X_{1} \backslash z_{0}\right)$ is evaluated. Conditional on the draw for the state variables, the predicted value for the variables $\hat{X}_{i 1}^{M}$ can be computed using the observation equation and the prediction error decomposition is used to evaluate the likelihood $W^{m}$. The update step involves a draw from the density $f\left(\Phi_{1} \backslash z_{1}\right)$. This is done by sampling with replacement from the sequence of particles with the re-sampling probability given by $\frac{W^{m}}{\sum_{m=1}^{M} W^{m}}$. This re-sampling step updates the draws for $\Phi$ based on information contained in the data for that time period. By the law of large numbers the likelihood function for the observation can be approximated as $\ln l i k_{t}=\ln \frac{\sum_{m=1}^{M} W^{m}}{M}$. 


\section{B Dataset}

The full list of the 350 data series, along with their FAME codes, is presented below. This appendix provides an overview of the dataset. The dataset contains data on real activity and inflation. We also include some indicators of money and key asset prices. As shown in the table below we take the first log difference of non-stationary series.

Real activity data includes real GDP, industrial production (with a broad sectoral break down), imports and exports, investment and real household consumption expenditure. The dataset includes a very detailed sectoral breakdown of consumption quantities. The data is obtained from the Office of National Statistics (ONS).

Inflation data includes the main price indices (GDP deflator, CPI, RPI and RPIX) and components of the consumption deflator. ONS and the Bank of England are the main sources for the data.

Money data for the U.K. includes M0 and M4, with a sectoral breakdown of the latter. This data is obtained from the Bank of England.

The asset price data includes house prices, stock prices, exchange rates (pounds in terms of US dollars, Euros, Yen, Canadian and Australian Dollars) and the term structure of interest rates. The data are obtained from the Global Financial Database and the Bank of England.

\begin{tabular}{|l|l|l|}
\hline NR & $\begin{array}{l}\text { FAME CODE } \\
\text { log-diff. unless } \\
\text { otherwise stated }\end{array}$ & SERIES NAME \\
\hline 1 & NMRY & General Government: Final consumption expenditure \\
2 & GDQB & ESA95 Output Index: F: Construction: \\
3 & IKBK & Balance of Payments: Trade in Goods \& Services: Total exports \\
4 & IKBL & Balance of Payments: Imports: Total Trade in Goods \& Services \\
5 & NPQT & Total Gross Fixed Capital Formation \\
6 & ABMI & Gross Domestic Product: chained volume measures \\
7 & CKYY & IOP: Industry D: Manufacturing: CVMSA NAYear \\
8 & GDQH & SA95 Output Ind.: I : Transport storage \& communication \\
9 & GDQS & SA95 Output Ind.: G-Q: Total \\
10 & GDQE & ESA95 Output Ind.: G \& H: Distrib., hotels \& catering; repairs \\
11 & CKYW & IOP: Industry C,D,E: All production industries \\
12 & CKYZ & IOP: Industry E: Electricity, gas and water supply: \\
13 & CKZA & IOP: Industry DA: Manuf of food, drink \& tobacco \\
14 & CKZF & IOP: Industry DF: Manuf coke/petroleum prod/nuclear fuels \\
15 & CKZG & IOP: Industry DG: Manuf of chemicals \& man-made fibres \\
16 & ABJR & Household final consumption expenditure \\
17 & NPEL & Business investment \\
\hline \multicolumn{2}{|l|}{ Household final consumption expenditure:durable goods (volumes) } \\
\hline 18 & UTID & Total \\
19 & LLKX & All furnishing \& household \\
20 & ATQX & Furniture and households \\
21 & ATRD & Carpets and other floor coverings \\
22 & XYJP & Major household appliances \\
23 & XYJR & Major tools and equipment \\
24 & LLKY & All Health \\
25 & UWIC & Therapeutic appliances and equipment \\
& & \\
\hline
\end{tabular}




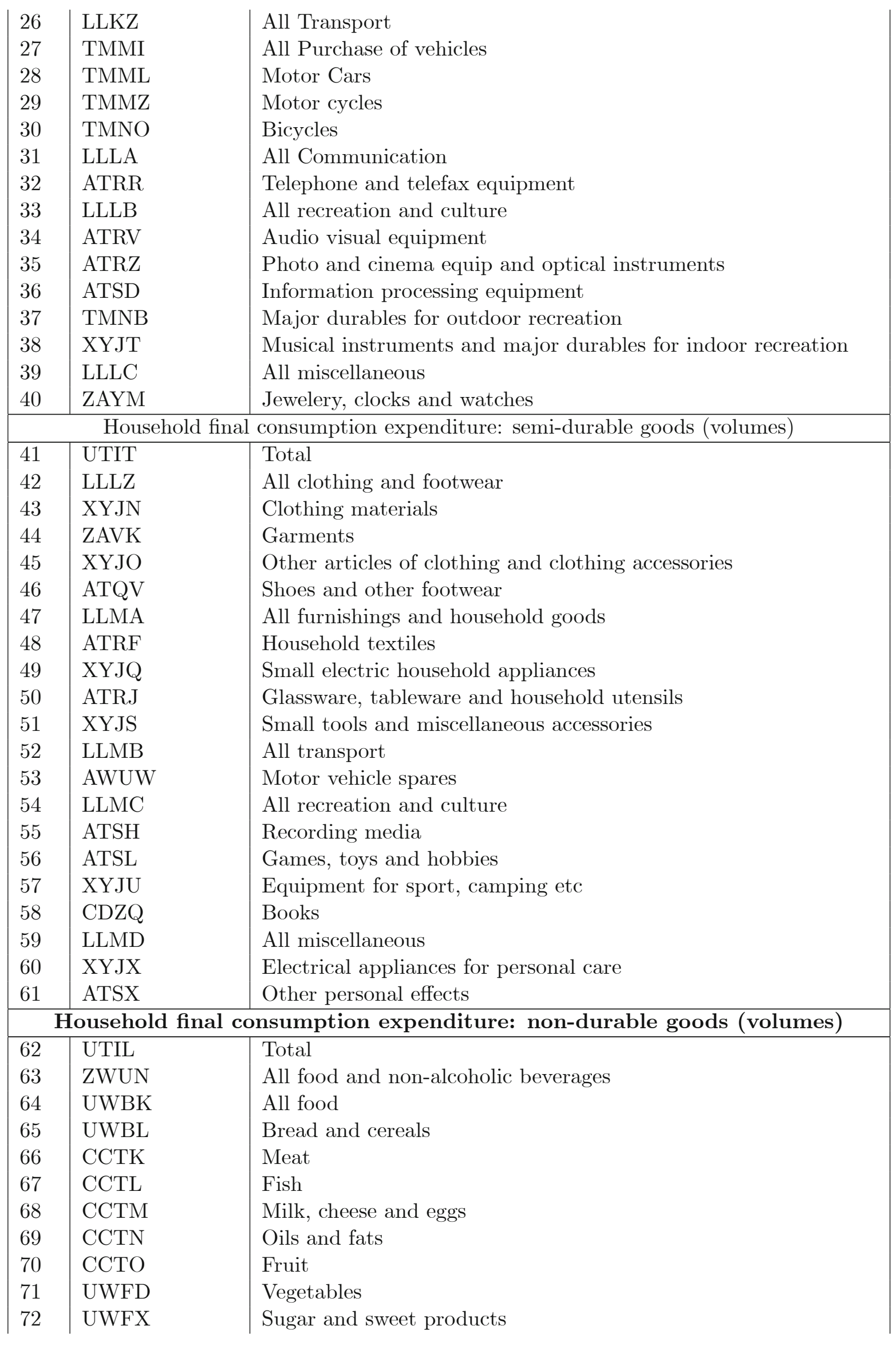




\begin{tabular}{|c|c|c|}
\hline & & \\
\hline 73 & UWGH & Food products n.e.c. \\
\hline 74 & UWGI & All non-alcoholic beverages \\
\hline 75 & CCTT & Coffee, tea and cocoa \\
\hline 76 & CCTU & Mineral, water and soft drinks \\
\hline 77 & ZAKY & All alcoholic beverages and tobacco \\
\hline 78 & UUIS & Spirits \\
\hline 79 & UTHW & Wine, cider and sherry \\
\hline 80 & UUVG & Beer \\
\hline 81 & ZWUP & Tobacco \\
\hline 82 & LLLL & All Housing, water, electricity, gas and other fuels \\
\hline 83 & ATUA & Materials for the maintenance and repair of the dwelling \\
\hline 84 & UTZN & Water supply \\
\hline 85 & ZWUR & All electricity, gas and other fuels \\
\hline 86 & CCUA & Electricity \\
\hline 87 & LTZA & Gas \\
\hline 88 & LTZC & Liquid fuels \\
\hline 89 & TTAB & Solid fuels \\
\hline 90 & LLLM & All furnishing and household goods \\
\hline 91 & UWHO & Non-durable household goods \\
\hline 92 & LLLN & All health \\
\hline 93 & UTXP & Pharmaceutical products \\
\hline 94 & UWIB & Other medical products \\
\hline 95 & LLLO & All transport \\
\hline 96 & CCTY & Vehicle fuels and lubricants \\
\hline 97 & LLLP & All recreation and culture \\
\hline 98 & AWUX & Gardens, plants and flowers \\
\hline 99 & UWKQ & Pets and related products \\
\hline 100 & CDZY & Newspapers and periodicals \\
\hline 101 & XYJV & Miscellaneous printed matter \\
\hline 102 & XYJW & Stationery and drawing materials \\
\hline 103 & LLLQ & All miscellaneous \\
\hline 104 & ATSP & Other products for personal care \\
\hline \multicolumn{3}{|c|}{ Household final consumption expenditure: services (volumes) } \\
\hline 105 & UTIP & Total \\
\hline 106 & LLLR & All clothing and footwear \\
\hline 107 & UWHI & Clothing, repair and hire of clothing \\
\hline 108 & AWUY & Repair and hire of footwear \\
\hline 109 & LLLS & All housing, water, electricity, gas and other fuels \\
\hline 110 & ZAVQ & All actual rentals for housing \\
\hline 111 & GBFG & Actual rentals paid by tenants \\
\hline 112 & GBFK & All imputed rentals for housing \\
\hline 113 & CCUO & Imputed rentals of owner-occupiers \\
\hline 114 & GBFN & Other imputed rentals \\
\hline 115 & AWUZ & Services for the maintenance and repair of the dwelling \\
\hline 116 & UWHK & Refuse collection \\
\hline 117 & UTZX & Sewerage collection \\
\hline 118 & LLLT & All furnishings and household services \\
\hline 119 & UWHM & Repair of furniture, furnishings and floor coverings \\
\hline 120 & UWHN & Repair of household appliances \\
\hline
\end{tabular}




\begin{tabular}{|c|c|c|}
\hline 121 & UWIA & Domestic and household services \\
\hline 122 & LLLU & All health \\
\hline 123 & ZAWG & All out-patient services \\
\hline 124 & ZAWI & Medical services \\
\hline 125 & ZAWK & Dental services \\
\hline 126 & UTMH & Paramedical services \\
\hline 127 & UTYF & Hospital services \\
\hline 128 & LLLV & Total transport \\
\hline 129 & AWVA & Vehicle maintenance and repair \\
\hline 130 & ZAWQ & Other vehicle services \\
\hline 131 & ZAWS & All transport services \\
\hline 132 & AWVB & Railways \\
\hline 133 & ZAWU & Road \\
\hline 134 & AWVC & Air \\
\hline 135 & AWVD & Sea and inland waterway \\
\hline 136 & AWVE & Other \\
\hline 137 & LLLW & All communication \\
\hline 138 & CCVM & Postal services \\
\hline 139 & ZAWY & Telephone and telefax services \\
\hline 140 & LLLX & All recreation and culture \\
\hline 141 & UWKO & Repair of audio-visual, photo and information processing equip. \\
\hline 142 & UWKP & Maintenance of other major durables for recreation and culture \\
\hline 143 & UWLD & Veterinary and other services for pets \\
\hline 144 & ZAXI & All recreational and cultural services \\
\hline 145 & ZAXK & Recreational and sporting services \\
\hline 146 & ZAXM & Cultural services \\
\hline 147 & CCVA & Games of chance \\
\hline 148 & ZWUT & Education \\
\hline 149 & ZAXS & All restaurants and hotels \\
\hline 150 & ZAXU & All catering services \\
\hline 151 & ZAXW & Restaurants, cafes etc. \\
\hline 152 & ZAYC & Canteens \\
\hline 153 & ZAYE & Accommodation services \\
\hline 154 & LLLY & All miscellaneous \\
\hline 155 & CCVZ & Hairdressing salons and personal grooming establishments \\
\hline 156 & ZAYO & Social protection \\
\hline 157 & ZAYQ & All insurance \\
\hline 158 & UTYH & Life insurance \\
\hline 159 & ZAYS & Insurance connected with the dwelling \\
\hline 160 & ZAYU & Insurance connected with health \\
\hline 161 & ZAYW & Insurance connected with transport \\
\hline 162 & ZAZA & All financial services n.e.c. \\
\hline 163 & ZAZC & All financial services other than FISIM \\
\hline 164 & ZAZE & Other services n.e.c. \\
\hline \multicolumn{3}{|r|}{ DEFLATORS } \\
\hline 165 & FRAH & RPI Total Food \\
\hline 166 & FRAI & RPI Total Non-Food \\
\hline 167 & FRAK & RPI Total All items other than seasonal Food \\
\hline 168 & ROYJ & Wages \\
\hline
\end{tabular}




\begin{tabular}{|c|c|c|}
\hline & \multirow{3}{*}{ YBGB } & \multirow{2}{*}{$\begin{array}{l}\text { GDP deflator } \\
\text { CPI }\end{array}$} \\
\hline 169 & & \\
\hline 170 & & CPI \\
\hline 171 & ABJS & CONSUMPTION \\
\hline 172 & IMF data & Import prices \\
\hline 173 & IMF data & Export prices \\
\hline \multicolumn{3}{|c|}{ Household final consumption expenditure: durable goods (deflators) } \\
\hline 174 & UTKT & Total \\
\hline 175 & LLOS & All furnishing \& household \\
\hline 176 & AWQK & Furniture and households \\
\hline 177 & AWQL & Carpets and other floor coverings \\
\hline 178 & AWQN & Major household appliances \\
\hline 179 & AWQQ & Major tools and equipment \\
\hline 180 & LLOT & All Health \\
\hline 181 & AWQW & Therapeutic appliances and equipment \\
\hline 182 & LLOU & All Transport \\
\hline 183 & UTPP & All Purchase of vehicles \\
\hline 184 & AWRA & Motor Cars \\
\hline 185 & AWRB & Motor cycles \\
\hline 186 & AWRC & Bicycles \\
\hline 187 & LLOV & All Communication \\
\hline 188 & UTPT & Telephone and telefax equipment \\
\hline 189 & LLOW & All recreation and culture \\
\hline 190 & AWRM & Audio visual equipment \\
\hline 191 & AWRN & Photo and cinema equip and optical instruments \\
\hline 192 & AWRO & Information processing equipment \\
\hline 193 & AWRR & Major durables for outdoor recreation \\
\hline 194 & AWRS & Musical instruments and major durables for indoor recreation \\
\hline 195 & LLOX & All miscellaneous \\
\hline 196 & AWSL & Jewelery, clocks and watches \\
\hline \multicolumn{3}{|c|}{ Household final consumption expenditure: semi-durable goods (deflators) } \\
\hline 197 & UTLB & Total \\
\hline 198 & LLPU & All clothing and footwear \\
\hline 199 & AWPP & Clothing materials \\
\hline 200 & AWPQ & Garments \\
\hline 201 & AWPR & Other articles of clothing and clothing accessories \\
\hline 202 & AWPT & Shoes and other footwear \\
\hline 203 & LLPV & All furnishings and household goods \\
\hline 204 & UTPH & Household textiles \\
\hline 205 & AWQO & Small electric household appliances \\
\hline 206 & UTPJ & Glassware, tableware and household utensils \\
\hline 207 & AWQR & Small tools and miscellaneous accessories \\
\hline 208 & LLPW & All transport \\
\hline 209 & AWRD & Motor vehicle spares \\
\hline 210 & LLPX & All recreation and culture \\
\hline 211 & AWRP & Recording media \\
\hline 212 & AWRU & Games, toys and hobbies \\
\hline 213 & AWRV & Equipment for sport, camping etc \\
\hline 214 & AWSC & Books \\
\hline 215 & LLPY & All miscellaneous \\
\hline
\end{tabular}




\begin{tabular}{|c|c|c|}
\hline $\begin{array}{l}216 \\
217\end{array}$ & $\begin{array}{l}\text { AWSJ } \\
\text { AWSM }\end{array}$ & $\begin{array}{l}\text { Electrical appliances for personal care } \\
\text { Other personal effects }\end{array}$ \\
\hline \multicolumn{3}{|c|}{ Household final consumption expenditure: non-durable goods (deflators) } \\
\hline 218 & UTKX & Total \\
\hline 219 & UTJO & All food and non-alcoholic beverages \\
\hline 220 & UTOV & All food \\
\hline 221 & AWPB & Bread and cereals \\
\hline 222 & AWPC & Meat \\
\hline 223 & AWPD & Fish \\
\hline 224 & AWPE & Milk, cheese and eggs \\
\hline 225 & AWPF & Oils and fats \\
\hline 226 & AWPG & Fruit \\
\hline 227 & AWPH & Vegetables \\
\hline 228 & AWPI & Sugar and sweet products \\
\hline 229 & AWPJ & Food products n.e.c. \\
\hline 230 & UTOW & All non-alcoholic beverages \\
\hline 231 & AWPK & Coffee, tea and cocoa \\
\hline 232 & AWPL & Mineral, water and soft drinks \\
\hline 233 & UTJP & All alcoholic beverages and tobacco \\
\hline 234 & AWPM & Spirits \\
\hline 235 & AWPN & Wine, cider and sherry \\
\hline 236 & AWPO & Beer \\
\hline 237 & UTOY & Tobacco \\
\hline 238 & LLPG & All Housing, water, electricity, gas and other fuels \\
\hline 239 & AWPZ & Materials for the maintenance and repair of the dwelling \\
\hline 240 & AWQB & Water supply \\
\hline 241 & UTPF & All electricity, gas and other fuels \\
\hline 242 & AWQF & Electricity \\
\hline 243 & AWQG & Gas \\
\hline 244 & AWQH & Liquid fuels \\
\hline 245 & AWQI & Solid fuels \\
\hline 246 & LLPH & All furnishing and household goods \\
\hline 247 & AWQS & Non-durable household goods \\
\hline 248 & LLPI & All health \\
\hline 249 & AWQU & Pharmaceutical products \\
\hline 250 & AWQV & Other medical products \\
\hline 251 & LLPJ & All transport \\
\hline 252 & AWRE & Vehicle fuels and lubricants \\
\hline 253 & LLPK & All recreation and culture \\
\hline 254 & AWRW & Gardens, plants and flowers \\
\hline 255 & AWRX & Pets and related products \\
\hline 256 & AWSD & Newspapers and periodicals \\
\hline 257 & AWSJ & Stationery and drawing materials \\
\hline 258 & LLPL & All miscellaneous \\
\hline 259 & AWSK & Other products for personal care \\
\hline \multicolumn{3}{|c|}{ Household final consumption expenditure: services (deflators) } \\
\hline 260 & UTKZ & Total \\
\hline 261 & LLPM & All clothing and footwear \\
\hline 262 & AWPS & Clothing, repair and hire of clothing \\
\hline
\end{tabular}




\begin{tabular}{|c|c|}
\hline 263 & AWPL \\
\hline 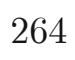 & LLPN \\
\hline 5 & AWPV \\
\hline 6 & AWPV \\
\hline 7 & UTPC \\
\hline & AWPX \\
\hline & AWPY \\
\hline 70 & AWQA \\
\hline 1 & AWQD \\
\hline & LLPO \\
\hline & AWQN \\
\hline 74 & AWQP \\
\hline 75 & AWQT \\
\hline 6 & LLPP \\
\hline 7 & UTPN \\
\hline 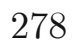 & AWQX \\
\hline 79 & AWQY \\
\hline 30 & AWQZ \\
\hline & UTPO \\
\hline & LLPQ \\
\hline 33 & AWRF \\
\hline 4 & AWRG \\
\hline & UTPR \\
\hline & AWRH \\
\hline 5, & AWRI \\
\hline & AWRJ \\
\hline & AWRK \\
\hline & AWRL \\
\hline & LLPR \\
\hline & UTPS \\
\hline & UTPU \\
\hline & LLPS \\
\hline & AWRQ \\
\hline & AWRY \\
\hline & UTPY \\
\hline & AWRZ \\
\hline & AWSA \\
\hline & AWSB \\
\hline & UTJX \\
\hline & UTJY \\
\hline & UTQG \\
\hline & AWSG \\
\hline & AWSH \\
\hline & UTQH \\
\hline & LLPT \\
\hline & AWSI \\
\hline & UTQK \\
\hline & UTQL \\
\hline & AWSN \\
\hline
\end{tabular}

Repair and hire of footwear

All housing, water, electricity, gas and other fuels

All actual rentals for housing

Actual rentals paid by tenants

All imputed rentals for housing

Imputed rentals of owner-occupiers

Other imputed rentals

Services for the maintenance and repair of the dwelling

Sewerage collection

All furnishings and household services

Repair of furniture, furnishings and floor coverings

Repair of household appliances

Domestic and household services

All health

All out-patient services

Medical services

Dental services

Paramedical services

Hospital services

Total transport

Vehicle maintenance and repair

Other vehicle services

All transport services

Railways

Road

Air

Sea and inland waterway

Other

All communication

Postal services

Telephone and telefax services

All recreation and culture

Repair of audio-visual, photo and information processing equip.

Veterinary and other services for pets

All recreational and cultural services

Recreational and sporting services

Cultural services

Games of chance

Education

All restaurants and hotels

All catering services

Restaurants, cafes etc.

Canteens

Accommodation services

All miscellaneous

Hairdressing salons and personal grooming establishments

Social protection

All insurance

Life insurance 


\begin{tabular}{|c|c|c|}
\hline 312 & AWSO & Insurance connected with the dwelling \\
\hline 313 & AWSP & Insurance connected with health \\
\hline 314 & AWSQ & Insurance connected with transport \\
\hline 315 & UTQM & All financial services n.e.c. \\
\hline 316 & AWSS & All financial services other than FISIM \\
\hline 317 & UTQN & Other services n.e.c. \\
\hline \multicolumn{3}{|r|}{ MONEY SERIES } \\
\hline 318 & M4SA & M4 deposits Total \\
\hline 319 & M4ISA & M4 deposits PNFCs \\
\hline 320 & M4OSA & M4 deposits OFCs \\
\hline 321 & M4PSA & M4 deposits Households \\
\hline 322 & M4LISA & M4 lending Total \\
\hline 323 & M4LOSA & M4 lending PNFCs \\
\hline 324 & M4LPSA & M4 lending Households \\
\hline \multicolumn{3}{|r|}{ ASSET PRICES } \\
\hline 325 & & Real Nationwide house prices \\
\hline 326 & & UK FT-Actuaries Dividend Yield (w/GFD extension) \\
\hline 327 & & UK FT-Actuaries PE Ratio (w/GFD extension) \\
\hline 328 & GFD data & FTSE ALL Share Index \\
\hline 329 & IMF data & NEER \\
\hline 330 & GFD data & pounds/dollar \\
\hline 331 & GFD data & pounds/euro \\
\hline 332 & GFD data & pounds/yen \\
\hline 333 & Global fin. data & pounds/canadian dollar \\
\hline 334 & Global fin. data & pounds/australian dollar \\
\hline 335 & non-transformed & Bond Yield 6 Months \\
\hline 336 & non-transformed & Bond Yield 9 Months \\
\hline 337 & non-transformed & Bond Yield 12 Months \\
\hline 338 & non-transformed & Bond Yield 15 Months \\
\hline 339 & non-transformed & Bond Yield 18 Months \\
\hline 340 & non-transformed & Bond Yield 21 Months \\
\hline 341 & non-transformed & Bond Yield 24 Months \\
\hline 342 & non-transformed & Bond Yield 30 Months \\
\hline 343 & non-transformed & Bond Yield 36 Months \\
\hline 344 & non-transformed & Bond Yield 48 Months \\
\hline 345 & non-transformed & Bond Yield 60 Months \\
\hline 346 & non-transformed & Bond Yield 72 Months \\
\hline 347 & non-transformed & Bond Yield 84 Months \\
\hline 348 & non-transformed & Bond Yield 96 Months \\
\hline 349 & non-transformed & Bond Yield 108 Months \\
\hline 350 & non-transformed & Bond Yield 120 Months \\
\hline
\end{tabular}




\section{References}

Alvarez, Fernando and Francesco Lippi, 2009, Persistent Liquidity Effect and Long Run Money Demand, University of Chicago, mimeo.

Baumeister, Christiane, Philip Liu and Haroon Mumtaz, 2010, Changes in the Transmission of Monetary Policy: Evidence from a Time-Varying Factor-Augmented VAR, Bank of England working papers 401, Bank of England.

Benati, Luca, 2004, Evolving Post-World War II U.K. Economic Performance, Journal of Money Credit and Banking 36(4), 691-717.

Benati, Luca, 2008, The "Great Moderation" in the United Kingdom, Journal of Money, Credit and Banking 40(1), 121-147.

Benati, Luca and Paolo Surico, 2009, VAR Analysis and the Great Moderation, American Economic Review 99(4), 1636-52.

Bernanke, Ben, Jean Boivin and Piotr S. Eliasz, 2005, Measuring the Effects of Monetary Policy: A Factor-augmented Vector Autoregressive (FAVAR) Approach, The Quarterly Journal of Economics 120(1), 387-422.

Bianchi, Francesco, Haroon Mumtaz and Paolo Surico, 2009, Dynamics of the Term Structure of UK Interest Rates, Bank of England working papers 363, Bank of England.

Boivin, Jean, Marc P. Giannoni and Ilian Mihov, 2009, Sticky Prices and Monetary Policy: Evidence from Disaggregated US Data, American Economic Review 99(1), 350-84.

Canova, Fabio and Gianni De Nicolo, 2002, Monetary Disturbances Matter for Business Fluctuations in the G-7, Journal of Monetary Economics 49(6), 1131-1159.

Carter, Chris and Robert Kohn, 1994, On Gibbs Sampling for State Space Models, Biometrika 81(3), pp. 541-553.

Castelnuovo, Efrem and Paulo Surico, 2006, The Price Puzzle: Fact or Artefact?, Bank of England Working Paper no. 288.

Chib, Siddhartha, 1995, Marginal Likelihood from the Gibbs Output, Journal of the American Statistical Association 90(432), pp. 1313-1321.

Cogley, Timothy, Giorgio E. Primiceri and Thomas J. Sargent, 2010, Inflation-Gap Persistence in the US, American Economic Journal: Macroeconomics 2(1), 43-69.

Cogley, Timothy, Sergei Morozov and Thomas J. Sargent, 2005, Bayesian Fan Charts for U.K. Inflation: Forecasting and Sources of Uncertainty in an Evolving Monetary System, Journal of Economic Dynamics and Control 29(11), 1893-1925.

Cogley, Timothy and Thomas J. Sargent, 2005, Drift and Volatilities: Monetary Policies and Outcomes in the Post WWII U.S, Review of Economic Dynamics 8(2), 262-302.

Del Negro, Marco and Christopher Otrok, 2008, Dynamic factor models with time-varying parameters: measuring changes in international business cycles, Staff Reports 326, Federal Reserve Bank of New York. 
Fernandez-Villaverde, Jesus and Juan Rubio-Ramirez, 2008, How Structural Are Structural Parameters?, NBER Macroeconomics Annual 2007, Volume 22, NBER Chapters, National Bureau of Economic Research, Inc, pp. 83-137.

Forni, Mario and Luca Gambetti, 2010, Macroeconomic Shocks and the Business Cycle: Evidence from a Structural Factor Model, Center for Economic Research (RECent) 040, University of Modena and Reggio E., Dept. of Economics.

Jacquier, Eric, Nicholas G Polson and Peter E Rossi, 2002, Bayesian Analysis of Stochastic Volatility Models, Journal of Business \& Economic Statistics 20(1), 69-87.

Kim, Chang-Jin and Charles R. Nelson, 1999, State-Space Models with Regime Switching, MIT Press, Cambridge, Massachusetts.

Koop, G., M. H. Pesaran and S. M. Potter, 1996, Impulse Response Analysis in Nonlinear Multivariate Models, Journal of Econometrics 74, 119-47.

Leduc, Sylvain, Keith Sill and Tom Stark, 2007, Self-fulfilling Expectations and the Inflation of the 1970s: Evidence from the Livingston Survey, Journal of Monetary Economics $\mathbf{5 4}(2), 433-459$.

Lubik, Thomas and Frank Schorfheide, 2006, A Bayesian Look at the New Open Economy Macroeconomics, NBER Macroeconomics Annual 2005, Volume 20, NBER Chapters, National Bureau of Economic Research, Inc, pp. 313-382.

Mumtaz, Haroon and Paolo Surico, 2008, Evolving International Inflation Dynamics: Evidence from a Time-Varying Dynamic Factor Model, Bank of England working papers 341, Bank of England.

Primiceri, Giorgio E., 2005, Time Varying Structural Vector Autoregressions and Monetary Policy, Review of Economic Studies 72(3), 821-52.

Uhlig, Harald, 2005, What are the Effects of Monetary Policy on Output? Results From an Agnostic Identification Procedure, Journal of Monetary Economics 52(2), 381-419. 
